\title{
New Insights into the Source of the Makran Tsunami of 27 November 1945 from Tsunami Waveforms and Coastal Deformation Data
}

\author{
Mohammad Heidarzadeh $^{1}$ and Kenji Satake $^{1}$
}

\begin{abstract}
We constrain the source of the 27 November 1945 tsunami in the Makran Subduction Zone (MSZ) using available tsunami waveforms recorded on tide gauges at Mumbai (India) and Karachi (Pakistan), and that inferred at Port Victoria (Seychelles), and coseismic deformation data along the Makran coast. Spectral analysis of the tsunami waveforms shows that the tsunami governing period was $40-50 \mathrm{~min}$ at Karachi whereas it was around $22 \mathrm{~min}$ at Mumbai. The inferred tsunami waveform at Port Victoria also indicated a period of around $21 \mathrm{~min}$ for the tsunami. Tsunami numerical simulations from the previously proposed source models failed in reproducing the observed tsunami waveforms and coseismic deformation data. Sensitivity analysis showed that the source fault needs to be extended offshore into deep water in order to reproduce the first 22-min signal at Mumbai. Based on the inversion of the observed tsunami waveforms, we propose a foursegment fault with varying slip amounts as the final source. This source includes a slip of $4.3 \mathrm{~m}$ onshore near Ormara (Pakistan) and a slip of $10 \mathrm{~m}$ offshore at water depth of around $3,000 \mathrm{~m}$. The total fault length is $220 \mathrm{~km}$, and the average slip is $6.1 \mathrm{~m}$. This source, first, reproduces fairly well the observed tide gauge records at Mumbai and Karachi, second, produces $\sim 1 \mathrm{~m}$ of uplift at Ormara and $\sim 1 \mathrm{~m}$ of subsidence at Pasni, and third, gives a moment magnitude of 8.3 for the earthquake, which is in the acceptable range of seismic data. The computed $1 \mathrm{~m}$ uplift at Ormara is in the uplift range of 1-3 m reported in the literature. As the tide gauge stations were located in the far field, our proposed source explains mainly the tectonic source of the tsunami.
\end{abstract}

Key words: Makran earthquake of 27 November 1945, tsunami, Makran Subduction Zone, spectral analysis, Fourier analysis, wavelet analysis, tsunami waveform inversion, coseismic deformation.

\section{Introduction}

The Makran tsunami of November 1945 is of utmost importance for studying tsunami hazards in the northwestern Indian Ocean as it is the largest

1 Earthquake Research Institute (ERI), The University of Tokyo, 1-1-1 Yayoi, Bunkyo-ku, Tokyo 113-0032, Japan. E-mail: mheidar@eri.u-tokyo.ac.jp instrumentally recorded tsunami in the region. The tsunami, generated by an $M 8.0-8.3$ earthquake (Byrne et al. 1992; Richter 1958) in the Makran Subduction Zone (MSZ), caused extensive damage and a death toll of 4,000 in the near field (НЕcK 1947) (Fig. 1). In the far field, it caused about 10 fatalities at Mumbai (NATURE 1945) and generated a wave height of about $30-50 \mathrm{~cm}$ at Seychelles, about 3,300 km away from the tsunami source (BEER and STAGG 1946). The earthquake origin time was 21:56 GMT on November 27, and the epicenter was at around $63.48^{\circ} \mathrm{E}$ and $25.15^{\circ} \mathrm{N}$ (BYRNE et al. 1992) (Fig. 1). As this event is the largest recorded earthquake in the region, it has been employed as the characteristic event for earthquake and tsunami hazard assessments for the Makran region.

There have been different reports for the magnitude of the 27 November 1945 Makran earthquake: $M$ 6.7 by Pendse (1946), $M 8 \frac{1}{4}$ by Gutenberg and Richter (1954), $M 8.3$ by Richter (1958), and $M 8.3$ by Duda (1965). Seismic waveform inversion by BYRNE et al. (1992) resulted in a moment magnitude range of $8.0-8.24$, which led them to an average magnitude of 8.1 for this earthquake. Thus, the magnitude from seismic analysis ranges from 8.0 to 8.3.

The 1945 Makran tsunami has been studied by several authors. HeIDARZADEH et al. (2008a) performed numerical modeling of the tsunami in order to interpret historical observations. NEETU et al. (2011) studied the trapped tsunami waves recorded on tide gauges at Karachi and Mumbai. JAISWAL et al. (2009) modeled this tsunami to study its effects on the Indian coasts. HeidARZADEH et al. (2009a) studied the tsunami hazards associated with the MSZ by assuming a 1945-type earthquake as the characteristic 


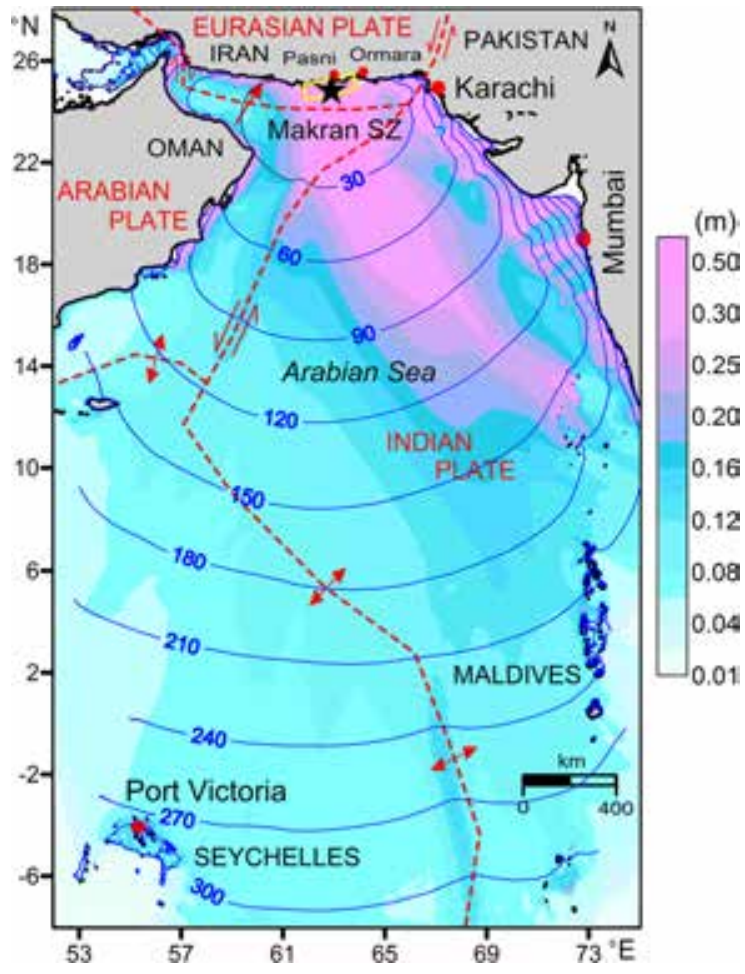

Figure 1

General tectonic setting of the northwestern Indian Ocean and the epicenter of the Makran earthquake of 27 November 1945 (asterisk) according to BYRNE et al. (1992). The yellow rectangle shows an approximation of the tsunami source. Color map shows the distribution of the maximum heights of the 1945 Makran tsunami as calculated by Heidarzadeh et al. (2008a). Contours with numbers are tsunami travel times in minutes. Dashed lines represent plate boundaries. $S Z$ subduction zone

tsunamigenic earthquake for the region. In some of the above studies, the tsunami source parameters were based on the seismic study by BYRNE et al. (1992). Details of the sources proposed by the aforesaid authors are summarized in Table 1 and shown schematically in Fig. 2a. Table 1 implies that the source parameters used by different authors significantly differ from each other. As an example, HeIDARZADEH et al. (2008a) assumed a slip of around $7 \mathrm{~m}$ on a very shallowly dipping fault plane, which generated a maximum seafloor deformation of around $2 \mathrm{~m}$ resulting in a tsunami runup height of around $1 \mathrm{~m}$ at Kutch (Figs. 5, 6 in Heidarzadeh et al. 2008a). However, JAISWAL et al. (2009) assumed a slip of around $15 \mathrm{~m}$, which generated a seafloor deformation of 6-7 m resulting in a runup height of around 3-4 m at Kutch (Figs. 3a, 4 in JaISwal et al. 2009).
Such a significant difference among the fault parameters of the 1945 Makran earthquake in previous studies can be problematic because this event has been used as the characteristic event for tsunami hazard assessment. This problem may partly arise from the unavailability of any tide gauge records for this tsunami; however, NeETU et al. (2011) recently published two tide gauge records for Mumbai and Karachi. In addition, the available coseismic deformation data were not used in previous studies (Table 1) to constrain the tsunami source. In such a context, this study aims to constrain the source of the 1945 Makran tsunami using available tide gauge records at Mumbai and Karachi, an inferred sea level record at Port Victoria (Fig. 1), as well as available field data on coseismic uplift/subsidence reported by PAGE et al. (1979). In the following, we apply spectral analysis to the tsunami waveforms, then perform dislocation modeling of the earthquake fault and numerical modeling of tsunami waves to examine how they can help to constrain the tsunami source.

\section{Tsunami Hazards in the Makran Region}

The tsunami hazards in the Makran region have been studied through different methods including archival, geological, and numerical methods, with emphasis on the November 1945 Makran tsunami. The geological field study by PAGE et al. (1979) showed that the region has experienced large-magnitude earthquakes as large as the 1945 event with a recurrence interval of around 125-250 years. The possibility of the occurrence of large-magnitude earthquakes at Makran was emphasized by QuiTTMEYER and JАCOB (1979) through a comprehensive seismological study. The mechanism of the 1945 earthquake was studied by BYRNE et al. (1992) through inversion of seismic body waves, indicating that the earthquake was of size $M w 8.1$ and ruptured around one-fifth of the subduction zone, i.e., $\sim 200 \mathrm{~km}$. The seismogenic potential of the MSZ was studied by SмIтн et al. (2013) by analyzing the thermal structure of the subduction zone. HoFFMANN et al. (2013) conducted a detailed archival study to document the effects of the 1945 tsunami on various coastlines of the Makran region and interviewed 
elderly eyewitnesses of this tsunami on the coast of Oman. Heidarzadeh et al. (2008a, b, 2009a, b) and HeidARZADEH and KiJKo (2011) studied the tsunami hazards associated with the MSZ using deterministic and probabilistic methods. By providing seismic reflection profiles of the MSZ, MoKhTARI (2014) studied the effect of possible splay faulting on tsunami hazards in the region. Geological studies on tsunami deposits by RAJENDRAN et al. (2013) led them to conclude that the western part of Makran is prone to large earthquakes. Shah-Hosseini et al. (2011) conducted a field survey of the Iranian coast of Makran and concluded that the origin of large coastal boulders was tsunami. Sedimentological studies by Donato et al. (2009) and Pilarczyk and Reinhardt (2012) located the deposits of the 1945 Makran tsunami in Sur Lagoon, Oman. The coast inside the Gulf of Oman was impacted by cyclone Gonu in 2007 (FriTz et al. 2010) and to a lesser extent by the 2004 Indian Ocean tsunami. Recently, a small tsunami was recorded in the region, possibly due to a submarine landslide following a Pakistan $M w 7.7$ inland earthquake, showing that even inland earthquakes can trigger landslide tsunamis in the Makran region (Heidarzadeh and Satake 2014). The Makran region is also at risk of far-field tsunamis (e.g., OKaL et al. 2006). This short summary of the available literature on the tsunami hazards in the MSZ indicates that the region has been home to large tsunamigenic earthquakes in the past.

\section{Data}

The data used here to constrain the tsunami source are of two types: (1) tsunami waveform data, and (2) coseismic deformation data. They are briefly introduced below.

\subsection{Tsunami Waveforms}

Our tsunami waveform data are those recorded on tide gauges at Mumbai (India) and Karachi (Pakistan) and one described at Port Victoria (Seychelles). The two tide gauge records were recently retrieved by NeEtu et al. (2011) (Fig. 2b, c). As shown, the Karachi tide gauge was out of order within the first hour after the earthquake, then started recording the waves. According to NeEtu et al. (2011), the tide gauge started recording before the arrival of the first wave. However, it is not known whether the early part of the tsunami waveform was recorded correctly or not. The two waveforms in NeEtu et al. (2011) were digitized with a sampling interval of $1.5 \mathrm{~min}$, and were de-tided using the tidal analysis package TASK (Tidal Analysis Software Kit) developed at the

Table 1

Fault parameters used for modeling the Makran tsunami of 27 November 1945 in previous studies

\begin{tabular}{|c|c|c|c|c|c|c|c|c|c|c|c|}
\hline \multirow[t]{2}{*}{ Source name } & \multirow[t]{2}{*}{$M w^{\mathrm{e}}$} & \multicolumn{2}{|l|}{ Location $^{\mathrm{f}}$} & \multirow[t]{2}{*}{ Water depth (m) } & \multirow[t]{2}{*}{ Length $(\mathrm{km})$} & \multirow[t]{2}{*}{ Width (km) } & \multirow[t]{2}{*}{ Slip (m) } & \multirow[t]{2}{*}{$\operatorname{Depth}^{\mathrm{g}}(\mathrm{km})$} & \multirow[t]{2}{*}{$\operatorname{Dip}\left(^{\circ}\right)$} & \multirow[t]{2}{*}{ Rake $\left(^{\circ}\right)$} & \multirow[t]{2}{*}{ Strike $\left(^{\circ}\right)$} \\
\hline & & Lon. $\left({ }^{\circ} \mathrm{E}\right)$ & Lat. $\left({ }^{\circ} \mathrm{N}\right)$ & & & & & & & & \\
\hline HDZ-2008 ${ }^{\mathrm{a}}$ & 8.4 & 64.01 & 25.06 & 50 & 200 & 100 & 7.3 & 20 & 5.5 & 90 & 240 \\
\hline JWL-2009 ${ }^{\mathrm{b}}$ & 8.6 & 63.90 & 24.05 & 2,000 & 200 & 100 & 15 & 30 & 15 & 90 & 270 \\
\hline $\mathrm{HDZ}-2009^{\mathrm{c}}$ & 8.1 & 64.17 & 24.45 & 2,000 & 130 & 70 & 6.6 & 27 & 7 & 89 & 246 \\
\hline NET-2011 ${ }^{\mathrm{d}}$ & 8.2 & 64.59 & 24.87 & 15 & 100 & 100 & 7 & 15 & 7 & 89 & 246 \\
\hline
\end{tabular}

${ }^{\text {a }}$ Heidarzadeh et al. (2008a)

b JAISWAL et al. (2009)

${ }^{c}$ Heidarzadeh et al. (2009a)

d NeETu et al. (2011)

e Moment magnitude calculated based on the seismic moment of the source fault; these values may differ from magnitude values reported by the authors in the respective articles

${ }^{\mathrm{f}}$ The southeast corner of the fault plane

g Upper depth of the fault 

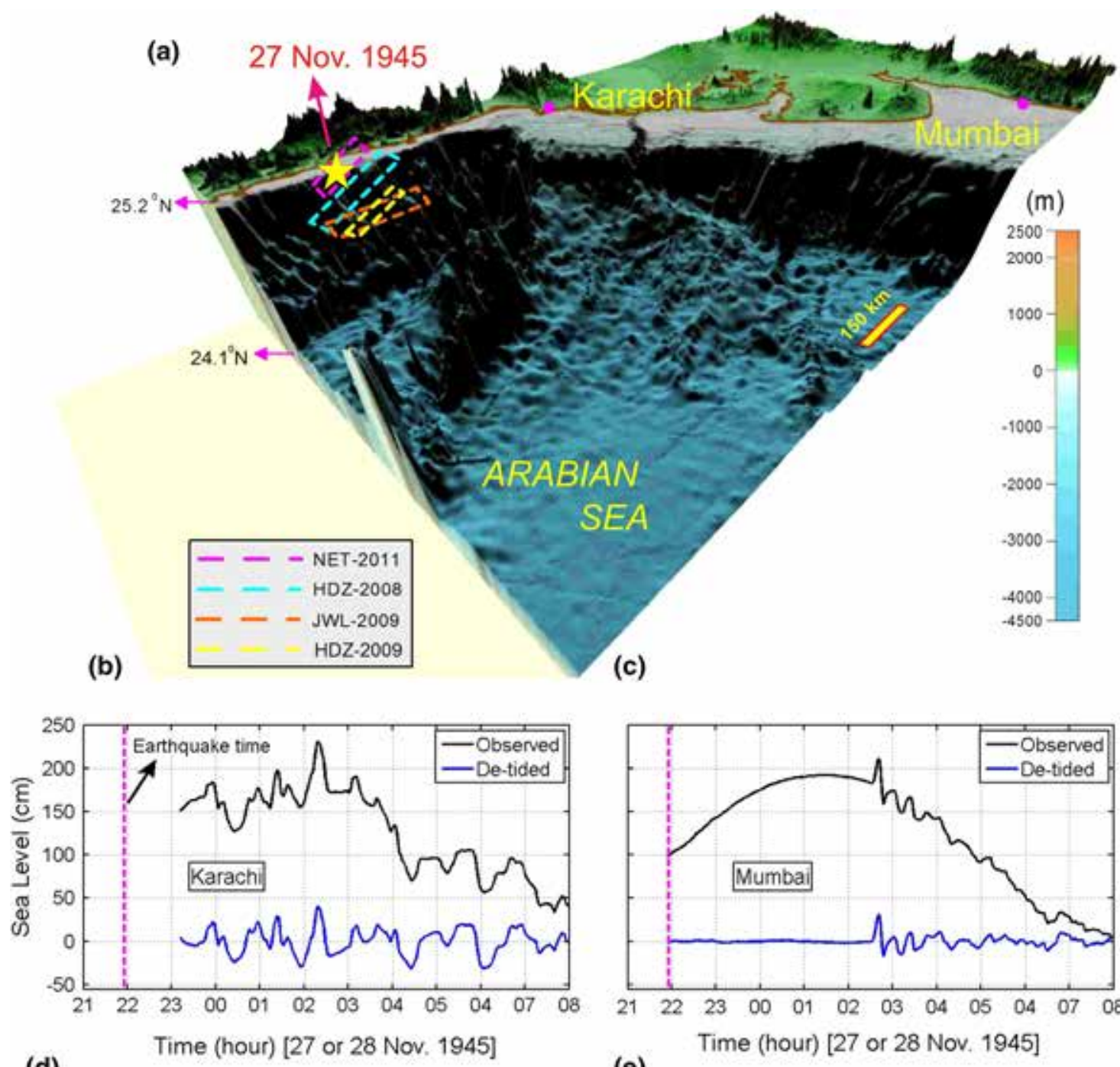

(d)

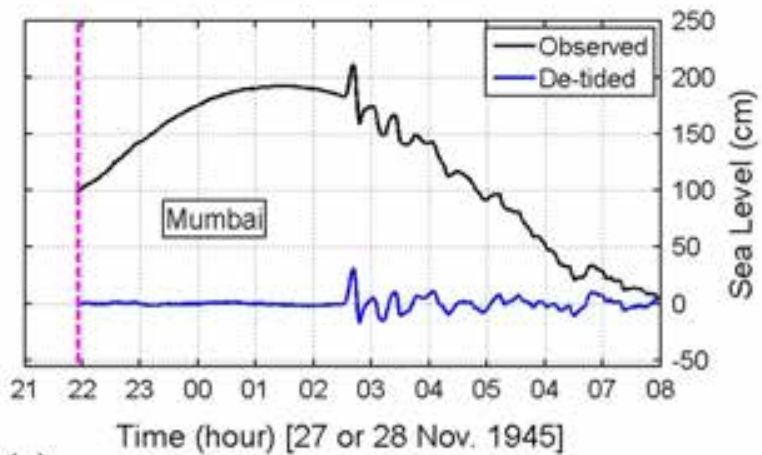

(e)
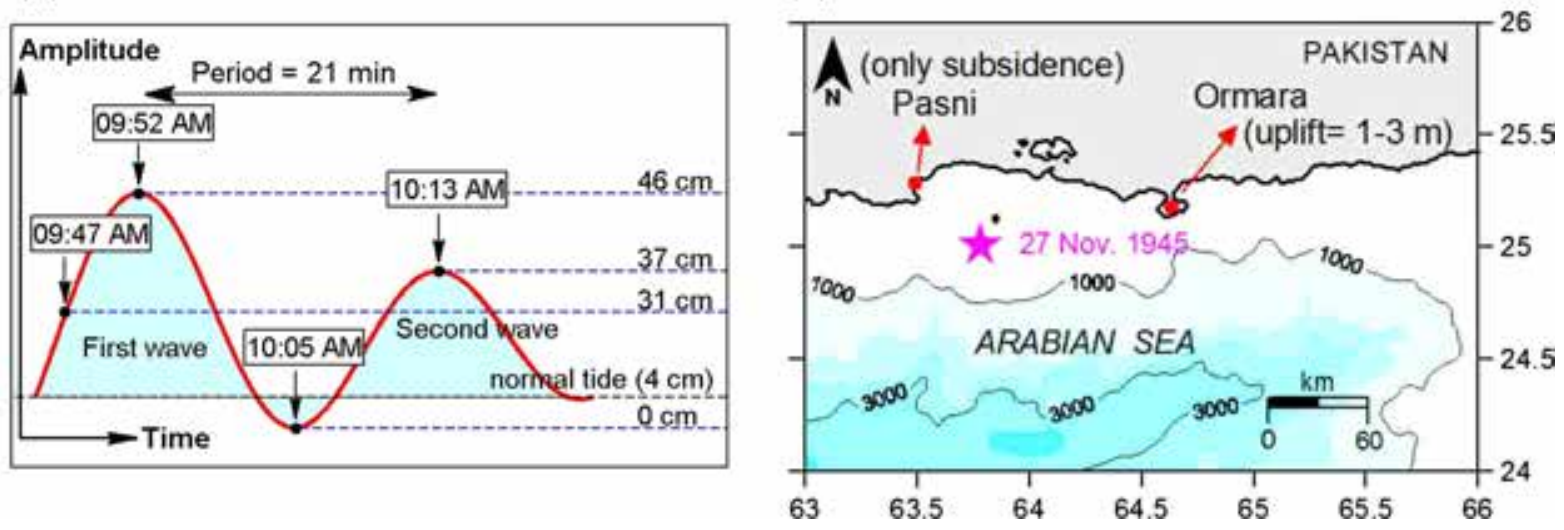
Figure 2

a Perspective view of the bathymetry of the northwestern Indian Ocean with projected faults proposed for the 1945 Makran tsunami in previous studies. Asterisk shows the epicenter of the earthquake. Blue, brown, yellow, and purple dashed rectangles are approximations of the tsunami source previously proposed by HEIDARZADEH et al. (2008a, 2009a), JaISwal et al. (2009), and NeEtu et al. (2011), respectively. b, c Tide gauge records of the Makran tsunami of November 1945 at Karachi and Mumbai, respectively. Purple dashed line represents the earthquake origin time. d Descriptive sea level observation of the 1945 Makran tsunami at Port Victoria, Seychelles as reported by BeER and StAGg (1946).

e Coseismic deformation as reported by PAGE et al. (1979)

Proudman Oceanographic Laboratory (UK) (BELL et al. 2000).

The descriptive sea level change at Seychelles was reported by BEER and StAGg (1946) as follows: "The Chief Meteorological Officer, Royal Air Force East Africa, has reported an interesting tidal irregularity observed by Captain A. Sauvage, port officer at Port Victoria, Mahe, Seychelles, on November 28, 1945, at about 10 a.m. local time. It appears that while the normal water-level corresponding with the state of tide at this time was $1.5 \mathrm{in} .[\sim 4 \mathrm{~cm}]$, the level observed at $9 \mathrm{~h} 47 \mathrm{~min}$ a.m. was $12 \mathrm{in}$. [ $\sim 31 \mathrm{~cm}]$. The water then rose to 18 in. [ $\sim 46 \mathrm{~cm}]$ at $9 \mathrm{~h} 52 \mathrm{~min}$, dropped to 0 at $10 \mathrm{~h} 5 \mathrm{~min}$ and rose again to $14.5 \mathrm{in}$. [ $\sim 37 \mathrm{~cm}]$ at $10 \mathrm{~h} 13 \mathrm{~min}$ a.m." This observation, which contains four sea level points at different times, is schematically shown in Fig. 2d, indicating a tsunami period of around $21 \mathrm{~min}$ for the sea level oscillations at Seychelles.

\subsection{Coseismic Deformation Data}

The coseismic deformation data are based on the geological field survey of the region by PAGE et al. (1979), which was conducted approximately 30 years after the earthquake. These field data indicate that Pasni experienced significant subsidence so that the coastline was moved about $100 \mathrm{~m}$ landward. PAGE et al. (1979) speculated that this subsidence was apparently generated by a submarine slide. PAGE et al. (1979) also reported an uplift of about 1-3 $\mathrm{m}$ at Ormara (Figs. 1, 2e). These uplift data were the results of interviews with local fishermen and represent the difference between tidal levels before and after the earthquake. It is clear that these measurements were associated with some errors, but no discussion was made by PAGE et al. (1979) about the amount of possible errors or how many sites were surveyed to reach this uplift value.

\section{Methodology}

Different methods have been applied in the past to obtain information about the source of a tsunami from its sea level records, such as Fourier analysis (e.g., Rabinovich 1997), wavelet analysis (e.g., HeIDarzadeh and Satake 2013a; Borrero and Geer 2013), forward tsunami modeling (e.g., Tinti et al. 1999), and tsunami waveform inversion (e.g., SATAKE et al. 2013). Here, our method is a combination of the aforesaid methods. When the available observations are limited (as in this study), application of tsunami waveform inversion alone is not fruitful because the stations used for inversion should provide adequate azimuthal coverage. It is evident that the observations available in this study do not provide adequate azimuthal coverage because only two waveforms are available: one to the east (i.e., Karachi) and the other to the southeast of the source (i.e., Mumbai). In this case, a combination of forward and inverse methods may provide more insight. Using forward modeling, the location of the tsunami source and fault parameters are fixed, then the slip distribution is calculated on the fault plane using waveform inversion. In fact, this method is a constrained inversion. We briefly discuss each method in the following.

\subsection{Spectral Analysis}

Two types of spectral analysis have been performed in this study: Fourier and wavelet analyses. Fourier analysis gives the peak periods of the waves, whereas wavelet analysis gives the evolution of tsunami energy over time and frequency domains; this is why wavelet analysis is also known as frequency-time analysis. A combination of wavelet and Fourier analyses has been reported to be fruitful in detecting tsunami governing periods (RABINOVICH and Thomson 2007; HeidarzadeH and SataKe 2013b). The waveform length is 9 and $10 \mathrm{~h}$ for Karachi and Mumbai, respectively. Wavelet analysis was performed using a Morlet mother function with 
wavenumber of 6 and a wavelet scale width of 0.10 (ToRrence and Compo 1998). For Fourier analysis, we apply two different methods: (1) the global wavelet spectrum provided by wavelet analysis, and (2) Welch's averaged modified periodogram by considering the Hamming window and overlaps (WeLCH 1967), for which we use the MATLAB command pwelch (MATHWORKS 2014).

\subsection{Tsunami Forward Modeling}

Tsunami forward modeling is a trial-and-error procedure to optimize tsunami source parameters (e.g., Heidarzadeh and Satake 2013b; Takahashi et al. 1995; TINTI et al. 1999). For tsunami modeling, we use a bathymetry grid of $925 \mathrm{~m} \times 925 \mathrm{~m}$ based on the 30-arcsecond GEBCO-08 bathymetric data (Ioc et al. 2003). Such a grid size is appropriate since the tsunami wavelengths are estimated to be around 200-300 km from the earthquake magnitude. In our grid system, the Karachi tide gauge is located at $66.985^{\circ} \mathrm{E}$ and $24.767^{\circ} \mathrm{N}$ at water depth of $7 \mathrm{~m}$ and the Mumbai station is located at $72.751^{\circ} \mathrm{E}$ and $18.906^{\circ} \mathrm{N}$ at water depth of $11 \mathrm{~m}$. The numerical model TUNAMI was used here (YALCINER et al. 2004), which solves the nonlinear shallow-water equations using a leap-frog scheme on a staggered grid system. We apply analytical formulas by OKADA (1985) to calculate seafloor and coastal deformation due to submarine faulting using earthquake source parameters. The calculated deformation was used as the initial condition for tsunami simulation as well as for comparison with the coseismic deformation reported by PAGE et al. (1979). The simulations were performed for a total simulation time of 6-7 h with a time step of $2.0 \mathrm{~s}$. Tsunami inundation on dry land is not included, hence a reflective boundary condition was imposed on the shoreline.

\subsection{Tsunami Waveform Inversion}

Optimization of the tsunami source was also performed by considering a heterogeneous slip distribution on the fault plane. In this context, the fault plane is divided into a number of subfaults, and the amount of slip on each subfault is calculated by minimizing the difference between observed and simulated waveforms at Karachi and Mumbai. First, tsunami waveforms due to a unit slip on each subfault are calculated at the two locations. We call these waveforms the Green's functions $g_{i j}(t)$, where $i=1,2, \ldots, M$ refers to observation stations and $j=1,2, \ldots, N$ refers to subfaults. Here $M(=2)$ and $N$ $(=4)$ are the total number of observation locations and subfaults, respectively. Then, it is assumed that the final simulated tsunami waveform at a particular location number $k$ [i.e., $Z_{k}(t)$ ] is a linear combination of the Green's functions at that location $\left[g_{k j}(t)\right]$ with different coefficients $\left(C_{j}\right)$, as indicated below (SATAKE 1987; SATAKE et al. 2013):

$$
Z_{k}(t)=\sum_{j=1}^{N} g_{k j}(t) C_{j},
$$

where the coefficients $C_{j}$ in Eq. 1 need to be calculated such that they minimize the difference between the waveform observed at location number $k$ [i.e., $\left.\eta_{k}(t)\right]$ and the simulated one [i.e., $\left.Z_{k}(t)\right]$. Because the Green's functions are calculated for a unit amount of slip, the coefficients $C_{j}$ are the final slip amounts on each subfault, and are calculated by taking into account all available observations as follows:

$$
\min : \sum_{i=1}^{M} \sum_{j=1}^{N}\left\|g_{i j}(t) C_{j}-\eta_{i}(t)\right\|_{2}^{2},
$$

where $C_{j} \geq 0$ and $\|\cdot\|_{2}$ denotes the Euclidean norm (KREYSZIG 2010). For performing this optimization, only the first waves at each location were used. For solving Eq. 2, we apply the nonnegative least-squares solver lsqnonneg from the optimization toolbox of the MATLAB software (MATHworks 2014). As two tsunami waveforms have different amplitudes, accuracy, and importance, we apply different weight factors on the waveforms as described in Sects. 7.1 and 7.2.

For regions with steep bathymetry slopes, it is more accurate to consider the effect of horizontal deformation in tsunami inversion (TANIOKA and Satake 1996). However, it is well known that the Makran region is characterized by gentle slopes and is the only subduction zone in the world that does not have a trench (HEIDARZADEH et al. 2008a). Hence, we do not consider such an effect in our inversion. 


\section{Results of Spectral Analysis and the Governing} Periods

The observed tide gauge waveforms at Karachi and Mumbai were first analyzed to study the tsunami characteristics at these locations. The spectra shown in Fig. 3 were calculated using two different methods: Fourier analysis using Welch's method (line plots in the bottom panels) and wavelet analyses (2D color maps and line plots to the right of them). Although the peak periods are the same in both methods, the amount of energy is different. This difference is due to the nature of Fourier and wavelet analyses; Fourier analysis gives the power of the tsunami over the entire record, whereas the wavelet analysis gives the time evolution of the tsunami energy. Thus, to determine the governing period of the tsunami at each station, we use the results of Fourier analysis given by the Welch algorithm. Based on Fig. 3, the three peak periods are around 22-25, 40-50, and 85-90 min for both the Karachi and Mumbai stations. For Karachi, the governing period is around 40-50 min, whereas it is around $22-25 \mathrm{~min}$ for Mumbai. This difference is also evident in the tsunami waveforms (Fig. 2b-d), which indicate that the first wave arriving at Mumbai was shorter in period than that arriving at Karachi. For both stations, a 90-min signal is also clear in the tsunami spectra in Fig. 3. The time interval between the two wave crests recorded at Port Victoria was $21 \mathrm{~min}$ (Fig. 2d), indicating that this is the tsunami period at this station.

Wavelet plots in Fig. 3 show that tsunami energy switched between the period bands of 22-25, 40-50, and 85-90 min at different times. At Karachi, most of the tsunami energy was concentrated around the period bands of 85-90 and 40-50 min throughout the waveform of $9 \mathrm{~h}$. At Mumbai, the signal with period of around 22-25 min is stronger than the 90-min signal during the first hour after tsunami arrival; later, the 90-min signal shows more strength than the 22-min one.

Tsunami source periods are usually dictated by the water depth at the location of the source and by

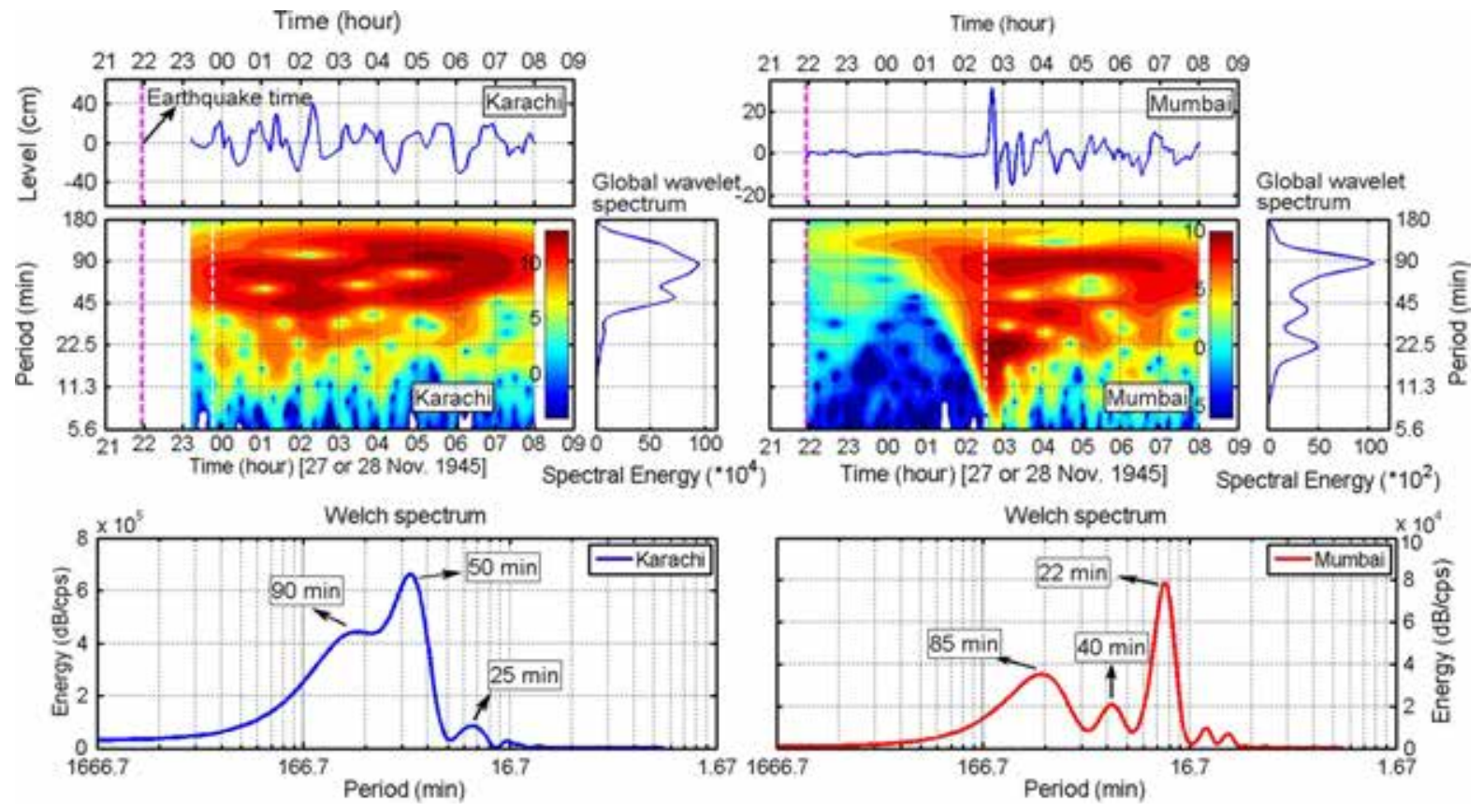

Figure 3

Results of spectral analyses for the two observed tide gauge records of the Makran tsunami of November 1945. Color plots show the results of wavelet analysis in $0.01 \times \log _{2}$ (spectral energy). The small panels to the right of wavelet plots are global wavelet spectra. Purple and white dashed lines represent the earthquake origin time and tsunami arrival times, respectively. Bottom panels are tsunami spectra calculated using the Welch algorithm 
(a) simulations using previously-proposed sources
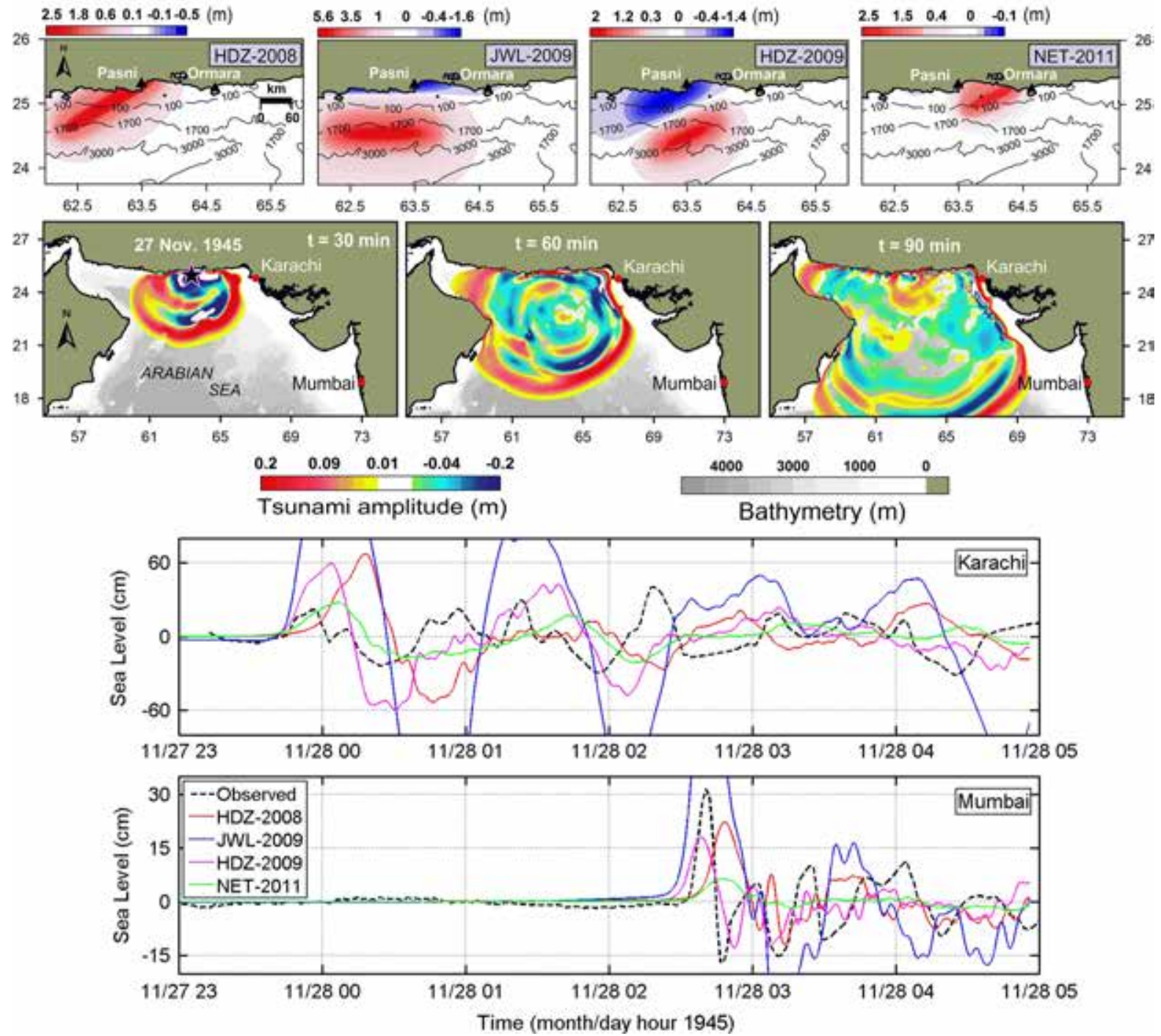

Figure 4

a Tsunami simulations for previously proposed source models for the 1945 Makran tsunami. Top row shows the initial seafloor deformation produced by different source models. Snapshots in middle row are based on simulations using the source HDZ-2009. Two bottom panels show comparison of observed (dashed lines) and simulated (colored solid lines) waveforms at Karachi and Mumbai. b Results of wavelet analyses for simulated waves from different source models. Small panels to the right of each wavelet plot are the global wavelet spectra (GWS). Vertical dashed line represents the earthquake origin time. Color bar shows $0.01 \times \log _{2}$ (spectral energy). Dashed and solid lines in tsunami spectra represent observed and simulated spectra, respectively. Numbers inside spectral plots show the factors used to normalize the amount of spectral energy for simulated waveforms in order to ease comparison between observed and simulated spectra. HDZ-2008, HDZ-2009,

JWL-2009, and NET-2011 represent HeidarZadeh et al. (2008a, 2009a), Jaiswal et al. (2009), and NeEtu et al. (2011), respectively

the dimensions of the tsunami source, and can be calculated using the tsunami phase velocity $(C)$ as follows:

$$
C=\sqrt{g d}
$$

$$
\begin{gathered}
C=\lambda / T, \\
T=2 L / \sqrt{g d},
\end{gathered}
$$

where $\lambda$ is the tsunami wavelength, $g$ is the gravitational acceleration of $9.81 \mathrm{~m} / \mathrm{s}^{2}, d$ is the ocean water 

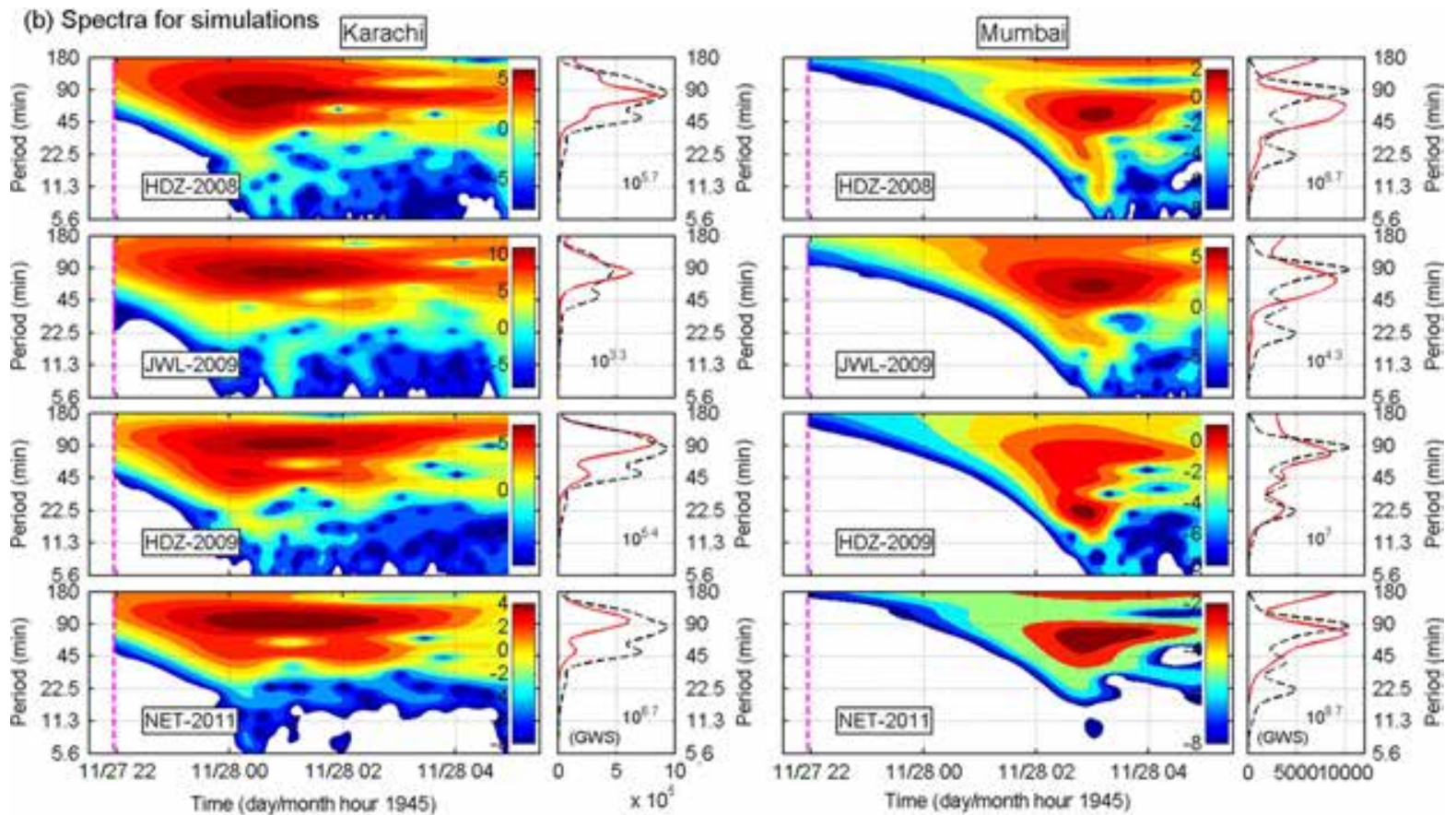

Figure 4

continued

depth at the location of the tsunami source, $T$ is the tsunami period, and $L$ is the source length. As indicated in Eq. 5, the tsunami wavelength $(\lambda)$ is usually twice the tsunami source length $(L)$. Equation 5 indicates that, the shallower the water depth at the tsunami source, the longer the period of the resulting tsunami; For example, by assuming an arbitrary source length of $100 \mathrm{~km}$ for a particular tsunami occurring at two different water depths of 100 and $2,000 \mathrm{~m}$, the periods of the resulting tsunamis will be 106 and $24 \mathrm{~min}$, respectively. The peak periods of the 1945 Makran tsunami, distributed in a wide range of 22-90 min, may indicate that the tsunami source is possibly extended from near-shore shallow waters of around $100 \mathrm{~m}$ to offshore deep waters of around 2,000-3,000 m.

\section{Results of Tsunami Forward Modeling}

\subsection{Simulations from Previously Proposed Source Models}

We compare the previously proposed source models in terms of their agreement between observed and simulated tsunami waveforms and their capabilities to reproduce the 1-3 $\mathrm{m}$ of uplift at Ormara (Fig. 4a). None of the source models can produce uplift at Ormara (Fig. 4a, top). The observed tsunami waveforms (Fig. 2b, c) show that the period of the first wave arriving at Karachi is $85-90 \mathrm{~min}$, and longer than that at Mumbai (22-25 min). Figure $4 \mathrm{a}$ (bottom) indicates that the source HDZ-2009 is the only one capable of reproducing a first 22-min signal at Mumbai (Fig. 4a); other models failed to reproduce the first 22-min signal at Mumbai. In terms of the polarity of the first wave (i.e., first elevation or depression wave), all of the source models give the same results as the observations. While the wave heights resulting from the three source models NET2011, HDZ-2008, and HDZ-2009 are almost on the same order, the source JWL-2009 yields wave heights up to five times larger than others.

According to Fig. 4a (bottom), the source HDZ2009 presents relatively better agreement between observed and simulated waveforms. The simulated arrival times and periods of the first waves at Karachi and Mumbai are close to the observed waveforms, although the simulated wave heights are smaller than 
those observed at Mumbai. In addition, spectral analysis shows that the computed spectrum at Mumbai resulting from the source HDZ-2009 is the only one showing three peak periods at around 22-25, 40-50, and 85-90 min (Fig. 4b). The spectra simulated using the source HDZ-2009 (Fig. 4b) are almost the same as the spectra observed at both stations. Therefore, we may conclude that the source HDZ2009 is more likely to represent the true source of the 1945 Makran tsunami. However, this source also fails to reproduce uplift at Ormara, similar to other source models. From the locations of the fault models (Table 1; Fig. 2a), it may be concluded that the tsunami source is more likely to be located in offshore deep waters, around latitude of $24.5^{\circ} \mathrm{E}$ where water depth is about $2,000 \mathrm{~m}$. This conclusion agrees with the results of spectral analysis presented in the previous section. The source HDZ-2009 will be the basis for further attempts to reach better agreement between observations and simulations.

\subsection{Sensitivity Analysis of the Source Model}

The target criteria for reaching an optimum source are: (1) agreement between observed and simulated waveforms, (2) generation of subsidence at Pasni and about 1-3 m of uplift at Ormara, and (3) keeping the moment magnitude of the earthquake in the magnitude range of 8.0-8.3 as reported in the literature (e.g., Byrne et al. 1992; Richter 1958; Duda 1965). Table 2 and Fig. 5a present details of 26 source scenarios which examine the effects of length/location, strike angle, width, depth, rake angle, dip angle, and slip on the tsunami waveforms at Karachi and Mumbai. Since the source HDZ-2009 produced better agreement between the observed and simulated waveforms (Fig. 4a, b), we changed the source parameters of HDZ-2009 to improve it through sensitivity analysis. The source parameters of HDZ2009 are mostly based on the seismic inversion study by BYRNE et al. (1992), which are associated with some errors. Therefore, we consider an error range for each parameter and study the sensitivity of the simulated tsunami waveforms to such error ranges. All scenarios are extended to Ormara in order to reproduce an uplift of around 1-3 m there (Table 2;
Fig. 5a-d). Results of sensitivity analysis are shown in Fig. 5e, whose main findings are:

1. Effect of length/location: by increasing the source length along the strike with fixed eastern end, the tsunami governing period decreases while the amplitude of the first wave increases. This is because a tsunami source in shallower water generates relatively longer periods compared with a tsunami source in deeper water, as explained in Sect. 5. Two scenarios (L-200 and L-237) yield waveforms similar to that observed at Mumbai, while none of the models can reproduce the observed amplitude at Karachi (Fig. 5e), hence we choose a source length of $220 \mathrm{~km}$. According to this test, the tsunami source needs to be extended into water depth of around 3,000 $\mathrm{m}$ in order to be able to reproduce the relatively short period of around $22 \mathrm{~min}$ at Mumbai.

2. Effect of strike angle: the two strike angles of $230^{\circ}$ and $245^{\circ}$ result in better agreement with observations at Mumbai in terms of arrival time and period (Fig. 5e). The source scenario ST-260, located in shallow water (Fig. 5a), produces a poor result (Fig. 5e). To choose our strike angle on an objective basis, we use the strike angle of $246^{\circ}$ as determined by inversion of seismic body waves (BYRNE et al. 1992), which is close to the values suggested by our sensitivity analysis.

3. Effect of source width: by increasing the fault width from 40 to $100 \mathrm{~km}$, the tsunami period remains almost the same, the wave amplitude increases, and the difference between the amplitudes of the first and second waves at Mumbai increases. Although the elevation of the first wave generated by scenario $\mathrm{W}-100$ is close to the observations, the following depression does not match well with the observations, indicating that a width of around $100 \mathrm{~km}$ is not appropriate. A source width of 50-70 km seems appropriate.

4. Effect of the upper depth of the fault: no significant effect can be seen on the simulated waveforms by changing the fault depth. However, by decreasing the top depth of the fault from 37 to $17 \mathrm{~km}$, the difference between the amplitudes of the first and second waves at Mumbai decreases. Two scenarios (h-30 and h-37) seem more appropriate (Fig. 5e). 
Table 2

Different source scenarios used for sensitivity analysis

\begin{tabular}{|c|c|c|c|c|c|c|c|c|c|c|c|c|c|}
\hline \multirow[t]{2}{*}{ Scenario name } & & \multicolumn{2}{|c|}{ Location $^{\mathrm{a}}$} & \multirow[t]{2}{*}{$\begin{array}{l}\text { Length } \\
(\mathrm{km})\end{array}$} & \multirow[t]{2}{*}{$\begin{array}{l}\text { Width } \\
(\mathrm{km})\end{array}$} & \multirow[t]{2}{*}{$\begin{array}{l}\text { Slip } \\
(\mathrm{m})\end{array}$} & \multirow[t]{2}{*}{$\begin{array}{l}\text { Depth }^{\mathrm{b}} \\
(\mathrm{km})\end{array}$} & \multirow[t]{2}{*}{$\begin{array}{l}\text { Strike } \\
\left({ }^{\circ}\right)\end{array}$} & \multirow[t]{2}{*}{$\begin{array}{l}\text { Rake } \\
\left({ }^{\circ}\right)\end{array}$} & \multirow[t]{2}{*}{$\begin{array}{l}\text { Dip } \\
\left(^{\circ}\right)\end{array}$} & \multicolumn{2}{|c|}{$\begin{array}{l}\text { Vertical } \\
\text { crustal } \\
\text { deformation }\end{array}$} & \multirow[t]{2}{*}{$M w^{\mathrm{c}}$} \\
\hline & & $\begin{array}{l}\text { Lon. } \\
\left({ }^{\circ} \mathrm{E}\right)\end{array}$ & $\begin{array}{l}\text { Lat. } \\
\left({ }^{\circ} \mathrm{N}\right)\end{array}$ & & & & & & & & Ormara & Pasni & \\
\hline \multirow[t]{4}{*}{ Length/location } & L-237 & 65.06 & 24.87 & 237 & 70 & 7.5 & 27 & 246 & 89 & 7.0 & +1.7 & -1.5 & 8.35 \\
\hline & L-200 & 65.06 & 24.87 & 200 & 70 & 7.5 & 27 & 246 & 89 & 7.0 & +1.7 & -1.5 & 8.30 \\
\hline & L-142 & 65.06 & 24.87 & 142 & 70 & 7.5 & 27 & 246 & 89 & 7.0 & +1.7 & -0.9 & 8.20 \\
\hline & L-120 & 64.97 & 25.07 & 120 & 70 & 7.5 & 27 & 246 & 89 & 7.0 & +2.0 & -0.2 & 8.15 \\
\hline \multirow[t]{3}{*}{ Strike } & ST-230 & 64.71 & 24.93 & 180 & 60 & 8.0 & 27 & 230 & 89 & 7.0 & +1.5 & -1.0 & 8.24 \\
\hline & ST-245 & 64.71 & 24.93 & 180 & 60 & 8.0 & 27 & 245 & 89 & 7.0 & +1.5 & -1.5 & 8.24 \\
\hline & ST-260 & 64.71 & 24.93 & 180 & 60 & 8.0 & 27 & 260 & 89 & 7.0 & +1.6 & +0.6 & 8.24 \\
\hline \multirow[t]{4}{*}{ Width } & $\mathrm{W}-40$ & 64.72 & 25.04 & 204 & 40 & 8.0 & 27 & 235 & 89 & 7.0 & +1.2 & -0.7 & 8.16 \\
\hline & $\mathrm{W}-60$ & 64.77 & 24.98 & 204 & 60 & 8.0 & 27 & 235 & 89 & 7.0 & +1.5 & -1.5 & 8.28 \\
\hline & $\mathrm{W}-80$ & 64.82 & 24.89 & 204 & 80 & 8.0 & 27 & 235 & 89 & 7.0 & +1.6 & -1.6 & 8.36 \\
\hline & W-100 & 64.86 & 24.81 & 204 & 100 & 8.0 & 27 & 235 & 89 & 7.0 & +1.7 & -0.7 & 8.43 \\
\hline \multirow[t]{4}{*}{ Depth } & h-17 & 64.79 & 25.02 & 204 & 50 & 8.0 & 17 & 235 & 89 & 7.0 & +1.7 & -0.8 & 8.23 \\
\hline & h-24 & 64.79 & 25.02 & 204 & 50 & 8.0 & 24 & 235 & 89 & 7.0 & +1.3 & -1.0 & 8.23 \\
\hline & h-30 & 64.79 & 25.02 & 204 & 50 & 8.0 & 30 & 235 & 89 & 7.0 & +1.3 & -1.1 & 8.23 \\
\hline & h-37 & 64.79 & 25.02 & 204 & 50 & 8.0 & 37 & 235 & 89 & 7.0 & +1.1 & -1.1 & 8.23 \\
\hline \multirow[t]{4}{*}{ Rake } & $\mathrm{R}-70$ & 64.79 & 25.02 & 204 & 50 & 8.0 & 17 & 235 & 70 & 7.0 & +2.0 & -0.8 & 8.23 \\
\hline & $\mathrm{R}-83$ & 64.79 & 25.02 & 204 & 50 & 8.0 & 17 & 235 & 83 & 7.0 & +1.9 & -0.9 & 8.23 \\
\hline & R-96 & 64.79 & 25.02 & 204 & 50 & 8.0 & 17 & 235 & 96 & 7.0 & +1.7 & -0.9 & 8.23 \\
\hline & $\mathrm{R}-110$ & 64.79 & 25.02 & 204 & 50 & 8.0 & 17 & 235 & 110 & 7.0 & +1.2 & -0.8 & 8.23 \\
\hline \multirow[t]{3}{*}{ Dip } & D-5 & 64.79 & 25.02 & 204 & 50 & 8.0 & 17 & 235 & 89 & 5.0 & +1.7 & -0.8 & 8.23 \\
\hline & D-7 & 64.79 & 25.02 & 204 & 50 & 8.0 & 17 & 235 & 89 & 7.0 & +1.7 & -0.8 & 8.23 \\
\hline & D-9 & 64.79 & 25.02 & 204 & 50 & 8.0 & 17 & 235 & 89 & 9.0 & +1.7 & -0.7 & 8.23 \\
\hline \multirow[t]{4}{*}{ Slip } & S-4 & 64.79 & 25.02 & 204 & 50 & 4.0 & 17 & 235 & 89 & 7.0 & +0.9 & -0.4 & 8.03 \\
\hline & S-6 & 64.79 & 25.02 & 204 & 50 & 6.0 & 17 & 235 & 89 & 7.0 & +1.4 & -0.6 & 8.14 \\
\hline & S-9 & 64.79 & 25.02 & 204 & 50 & 9.0 & 17 & 235 & 89 & 7.0 & +2.0 & -1.0 & 8.26 \\
\hline & S-11 & 64.79 & 25.02 & 204 & 50 & 11.0 & 17 & 235 & 89 & 7.0 & +2.5 & -1.2 & 8.32 \\
\hline Best & & 64.79 & 25.02 & 220 & 50 & 9.0 & 27 & 246 & 89 & 7.0 & +1.8 & -1.0 & 8.28 \\
\hline
\end{tabular}

Numbers in bold indicate parameters that change in each set of analyses

a The southeast corner of the fault plane

${ }^{\mathrm{b}}$ Upper depth of the fault

${ }^{c}$ Moment magnitude calculated by assuming rigidity of the earth of $3 \times 10^{11} \mathrm{dyn} / \mathrm{cm}^{2}$

We choose a depth of $27 \mathrm{~km}$ for the top of the fault, being among the seismic parameters of the 1945 earthquake determined by inversion of seismic body waves (BYRNE et al. 1992).

5. Effect of rake and dip angles: almost no effect can be seen on the simulated waveforms by changing the rake and dip angles (Fig. 5e). We apply the rake and dip angles of $89^{\circ}$ and $7^{\circ}$ calculated by BYRNE et al. (1992) for this earthquake.

6. Effect of slip: according to Fig. 5e, a slip of around $9-11 \mathrm{~m}$ is necessary to reproduce the observed amplitude at Mumbai. However, the simulated tsunami amplitudes from such scenarios are four times larger than the observed ones at Karachi.

Figure 5e shows that the simulated waveforms resulting from some of the source scenarios listed in Table 2 are similar to the observed ones. Out of the 26 different source scenarios listed in Table 2, we choose the best source parameters and list them in the last row of Table 2. A few other simulations were done to reach this best source. The results of tsunami simulations using these best source parameters are shown in Fig. 5e (bottom). Although the agreement between observed and simulated waveforms is good 

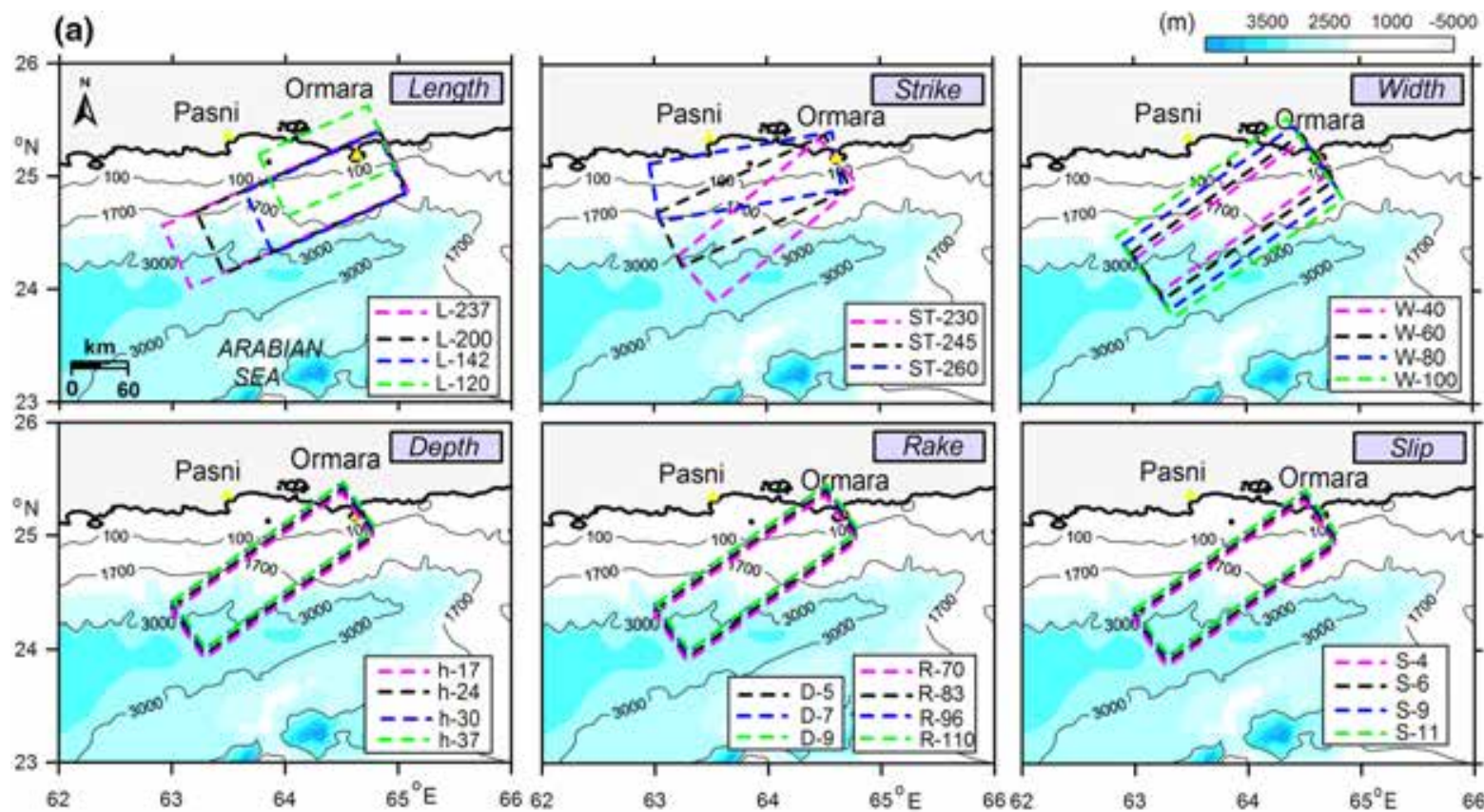

(b) $\begin{array}{llllllll}2.4 & 1.8 & 0.6 & 0.1 & -0.1 & -0.5 & -1.6 & (\mathrm{~m})\end{array}$
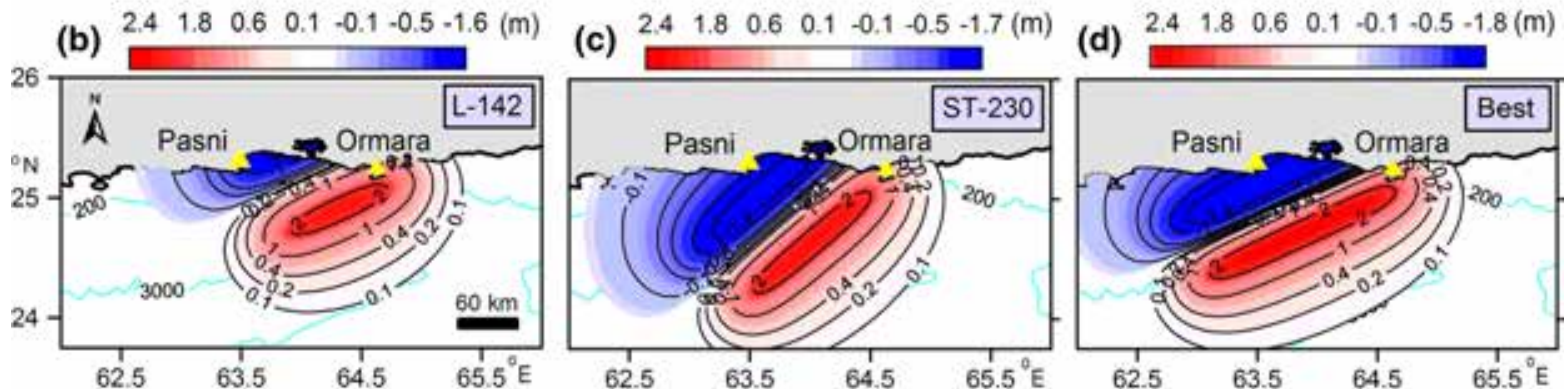

Figure 5

a Projection of different source scenarios used for sensitivity analysis according to Table 2. b, $\mathbf{c}$ Seafloor deformation due to selected source scenarios listed in Table 2. d Seafloor deformation due to the scenario "Best" in Table 2, which is the outcome of the sensitivity analysis. e Simulated tsunami waveforms at Karachi and Mumbai (solid colored lines) resulting from different source scenarios listed in Table 2 in comparison with the observed waveforms (dashed black lines)

much larger than the observed one. Using the source parameters obtained from the sensitivity analysis, we performed an inversion analysis to reach better agreement between observations and simulations.

\section{A Variable Slip Model}

\subsection{Tsunami Waveform Inversion}

The sensitivity analysis performed in the previous section paves the ground for performing this seismic parameters of the tsunamigenic fault and its extension. We divided the entire fault into four subfaults A-D (Fig. 6a), each having dimensions of $55 \mathrm{~km}$ (length) $\times 70 \mathrm{~km}$ (width). The tsunami Green's functions $\left(g_{i j}\right)$ from each subfault (Fig. 6c) were calculated using the fault parameters of strike $246^{\circ}$, rake $89^{\circ}$, dip $7^{\circ}$, upper depth of the fault $27 \mathrm{~km}$, and slip $1 \mathrm{~m}$. The two waveforms at Karachi and Mumbai are indicated by $i=1$ and 2, respectively. The Green's functions reveal useful information about the tsunami behavior; For example, the Green's 


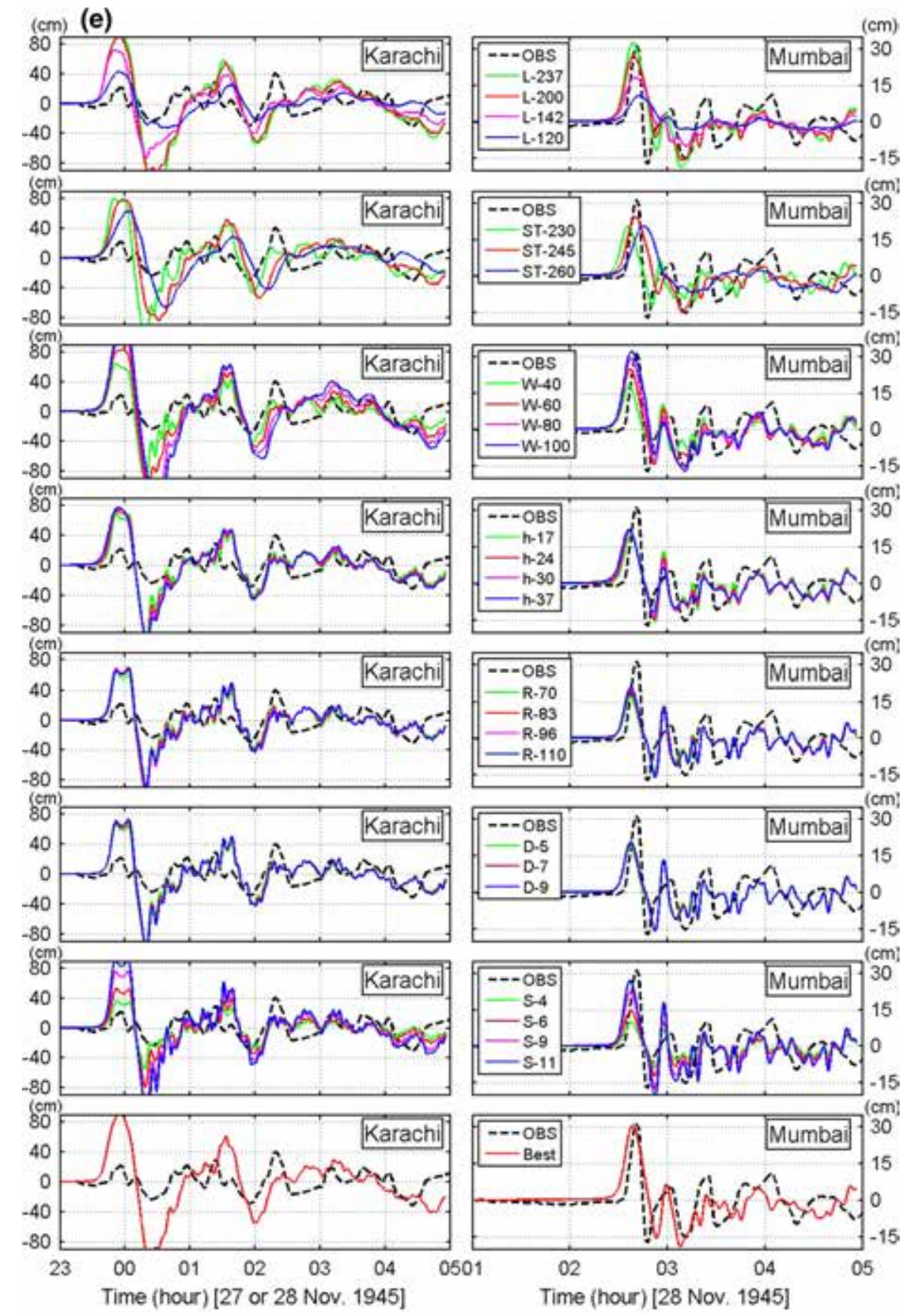

Figure 5

continued

function at Mumbai originating from the subfault in offshore deep water (i.e., $g_{2 \mathrm{~A}}$ ) contains relatively shorter periods compared with that originating from the subfault in near-shore shallow water (i.e., $g_{2 \mathrm{D}}$ ). To reproduce the first short period of $22 \mathrm{~min}$ at
Mumbai, we need a contribution from subfault A or B. In other words, if a source model lacks these offshore deep-water slips (e.g., HDZ-2008 in Fig. 4a), it will not be able to reproduce the 22-min signal observed at Mumbai. 
The results of waveform inversion for three different cases are shown in Fig. 6c-e. The first case uses only the Karachi waveform, the second case uses only the Mumbai waveform, and the third case uses the waveforms at both stations. In the first case, the simulated waveform at Karachi is similar to the observed one, but the simulated waveform at Mumbai is much smaller than the observed one (Fig. 6c). The slip distribution on each subfault indicates that subfaults A and B have the same slip $(1.5 \mathrm{~m})$ while subfault $\mathrm{D}$ has slip of $3.1 \mathrm{~m}$. In the second case, the agreement between observation and simulation is better for Mumbai than for Karachi (Fig. 6d). The slip on subfault A is much larger $(13.6 \mathrm{~m})$ than in the previous case, while the slip on subfault D stays the same. These cases indicate that it is hard to satisfy the two observed waveforms simultaneously by waveform inversion. The result of the third case, an inversion using both waveforms, is shown in Fig. 6e, which seems to be a median solution between the previous two cases (Fig. 6c, d). The slip on subfault A becomes $8.3 \mathrm{~m}$. The slip distribution and seafloor deformation from this solution are shown in Fig. 6a, and tsunami simulation using such a source results in the waveforms shown in Fig. 6f. While the agreement between simulation and observation is acceptable for Karachi, it is poor for Mumbai (Fig. 6f). However, the simulated and observed spectra agree well. We note that, in spectral analysis, usually the peak periods are important while the absolute amounts of spectral energy are not important as they strongly depend on factors such as the length of the time series and sampling intervals. To finalize the tsunami source, we need to reach a compromise between the two observed waveforms at Mumbai and Karachi. In the next section, we finalize the source by weighting the two tsunami waveforms.

\subsection{An Optimum Tsunami Source Model}

Inversion of the tsunami waveform at both locations yielded a compromised result; the simulated waveforms were larger than the observed one at Karachi but much smaller than the observed one at Mumbai (Fig. 6f). In addition, the simulated waveform at Mumbai shows similar amplitudes of
Figure 6

Results of tsunami waveform inversion. a Locations of four subfaults. Numbers on subfaults are slip amounts obtained from inversion of both Mumbai and Karachi waveforms. b Seafloor deformation due to the inversion result. $\mathbf{c}$ Results of inversion study using only the Karachi tide gauge record. Coefficients $C_{\mathrm{A}}$ to $C_{\mathrm{D}}$ represent the amount of slip on subfaults $A$ to $D$, respectively. d Results of inversion study using only the Mumbai tide gauge record. e Results of inversion study by using both tide gauges. f Results of tsunami simulations, both waveforms and spectra, using the solution shown in $\mathbf{e}$

the first and second waves, whereas the observed waveform shows that the first wave was four times larger than the second one. Because only two tsunami waveforms are available, and each of them shows different results, we need to examine the weight of each tsunami waveform in the inversion. To address the first problem, we give more weight to the Mumbai waveform, as inversion of the Mumbai waveform alone yielded larger slip $(13.6 \mathrm{~m})$ in subfault A. The result of tsunami simulation from inversion of only the Mumbai waveform is shown by blue waveforms in Fig. 7d. It can be seen that, while the amplitude of the first wave has increased at Mumbai, the second wave also becomes large and much larger than the observed one. The simulated waveform at Karachi is also larger than the observation. We noticed that the ratio between the amplitudes of the first and second waves at Mumbai is affected by the offshore slip (i.e., slips in subfaults A and B). We also note that the result of inversion of only the Karachi waveform required the same slip amount, albeit smaller, on subfaults A and B. Considering these features, we assumed the same slip on subfaults A and B, and performed a trialand-error analysis using different slip amounts on subfaults A and B to reach an optimum slip value of $10 \mathrm{~m}$ for both of them. The slip amounts on subfaults C and D are the same as those obtained using the inversion of both the Karachi and Mumbai waveforms (Fig. 6c). In our final source model (Fig. 7a-c, right), the slip distribution is closer to the results of inversion of only the Mumbai waveform (Fig. 7b, c, left) than that for only the Karachi waveform (Fig. 6c). In fact, we weight more the Mumbai waveform over the Karachi one in our final source, although this weighting is of qualitative nature. Application of different weights in tsunami inversion was previously used by some authors (e.g., 
(a)

(m) $3500 \quad 2500 \quad 1000 \quad-5000$

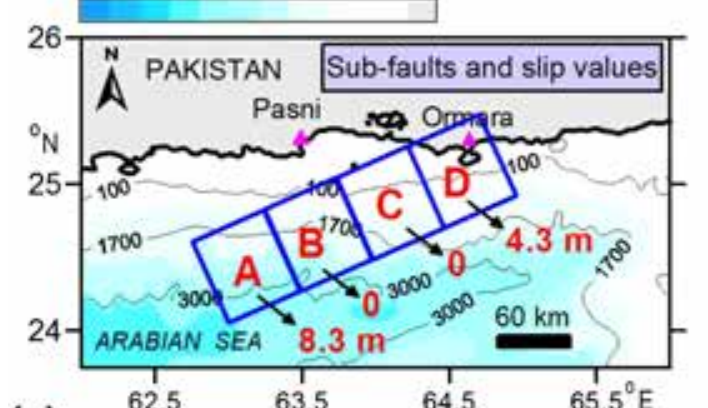

(b) $\begin{array}{lllllllll}2.1 & 1.4 & 0.6 & 0.06 & -0.1 & -0.5 & -1.3 & (\mathrm{~m})\end{array}$

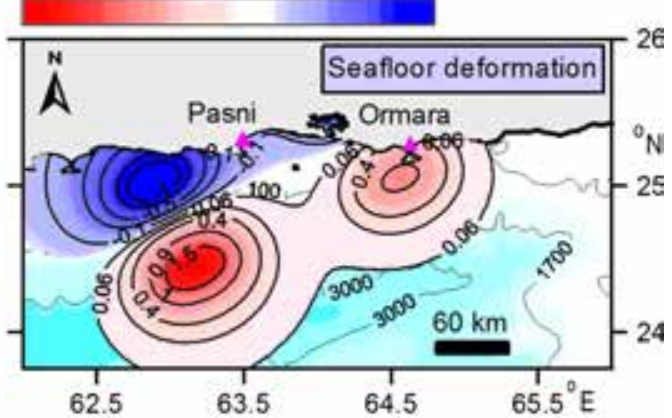

(c)

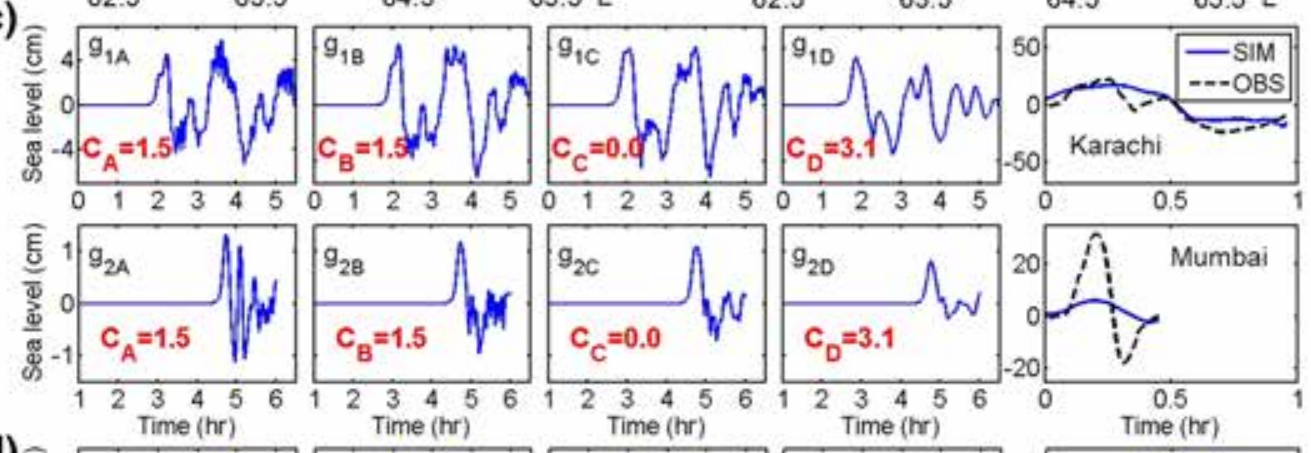

(d)
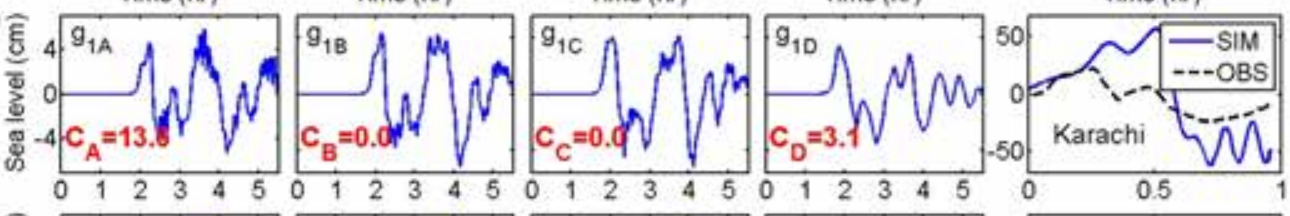

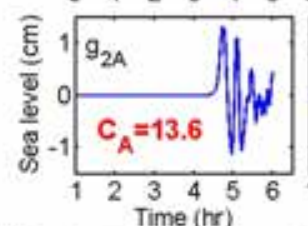
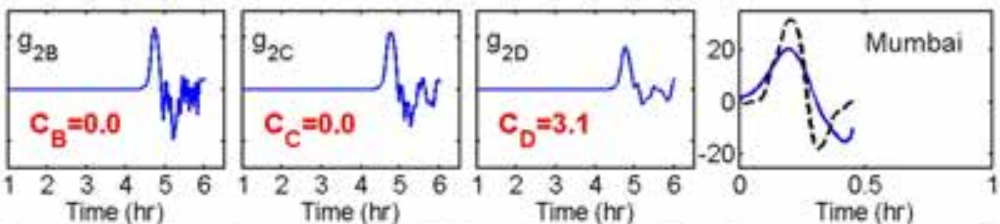

(e)
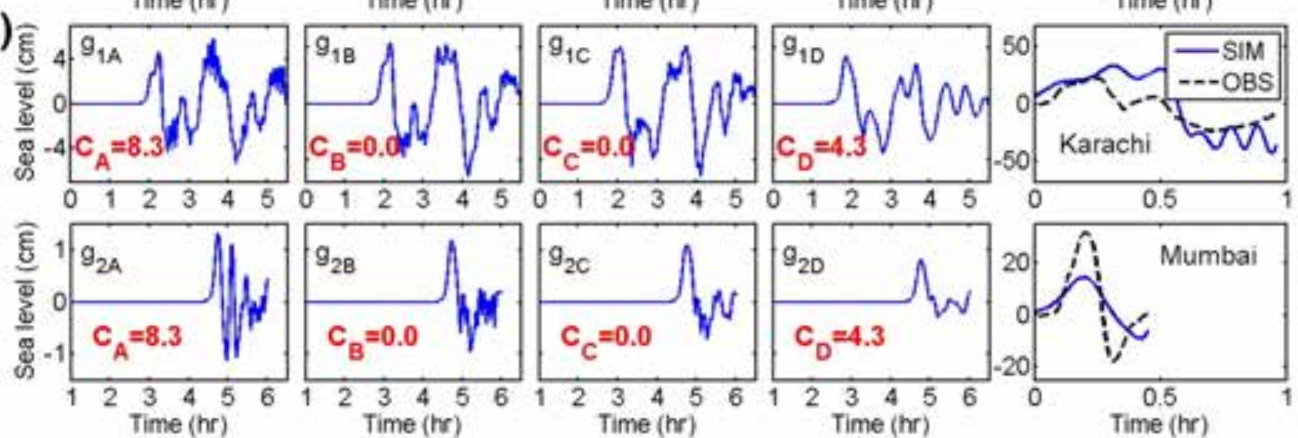

(f)

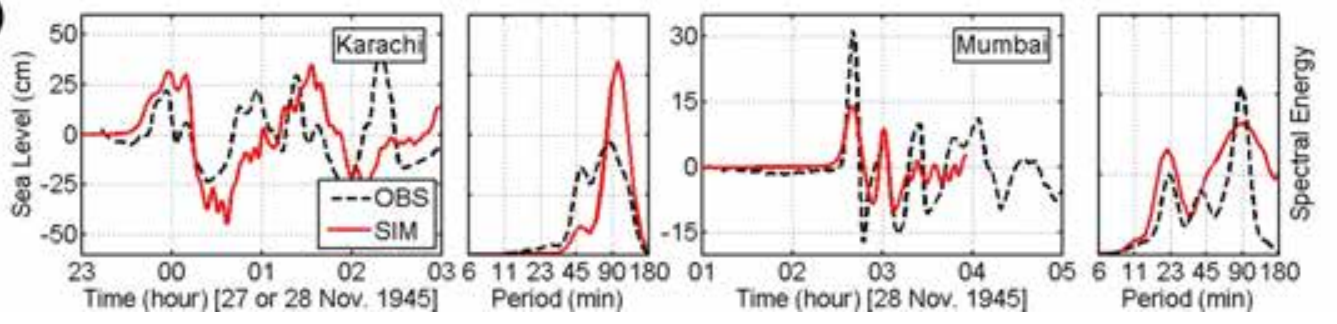




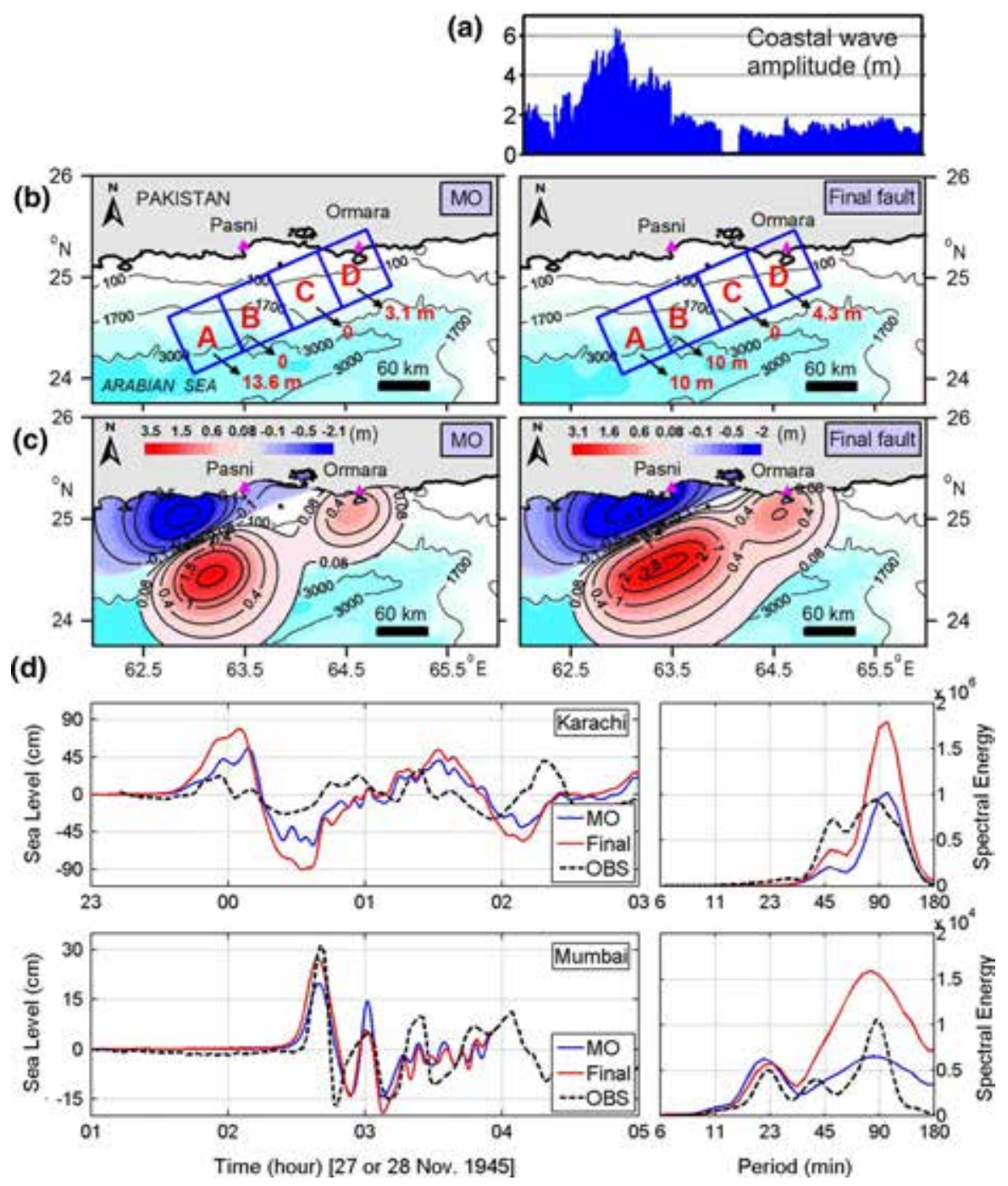

Figure 7

Distribution of coastal wave height (a), slip distribution (b), seafloor deformation (c), and simulated tsunami waveforms and spectra at Karachi and Mumbai (d) from the inversion result of the Mumbai waveform alone (left) and our final proposed source fault in Table 3 (right). $M O$ and $O B S$ stand for "Mumbai Only" and "Observations," respectively

SATAKe et al. 2013; FuJII et al. 2011). This final fault gives satisfactory results for both the first and second waves at Mumbai (Fig. 7d, red waveforms). The simulated spectra are also close to the observed ones at both Karachi and Mumbai. Although the simulated first arrival and shape of the waveform are close to the observations at Karachi, the simulated amplitudes are larger than the observed ones. The reason is that possibly the early stages of the Karachi waveform were not recorded correctly as the gauge was out of order before the tsunami arrival. In addition, the amplitude of around $20 \mathrm{~cm}$ at Karachi seems too small because the coastal wave height observed at Karachi during the 1945 tsunami was 1-1.5 m (HeIDARZADEH et al. 2008a).

In summary, the details of our final source are presented in Table 3 and are shown in Fig. $7 \mathrm{a}-\mathrm{c}$ (right) and $7 \mathrm{~d}$ (red waveforms). Based on Fig. 7, the final source extends from onshore near Ormara (Pakistan) to offshore at water depth of more than $3,000 \mathrm{~m}$, in agreement with the results of our spectral analysis in Sect. 5. 
Table 3

Summary of final source parameters proposed for the Makran tsunami of November 1945 based on the results of this study

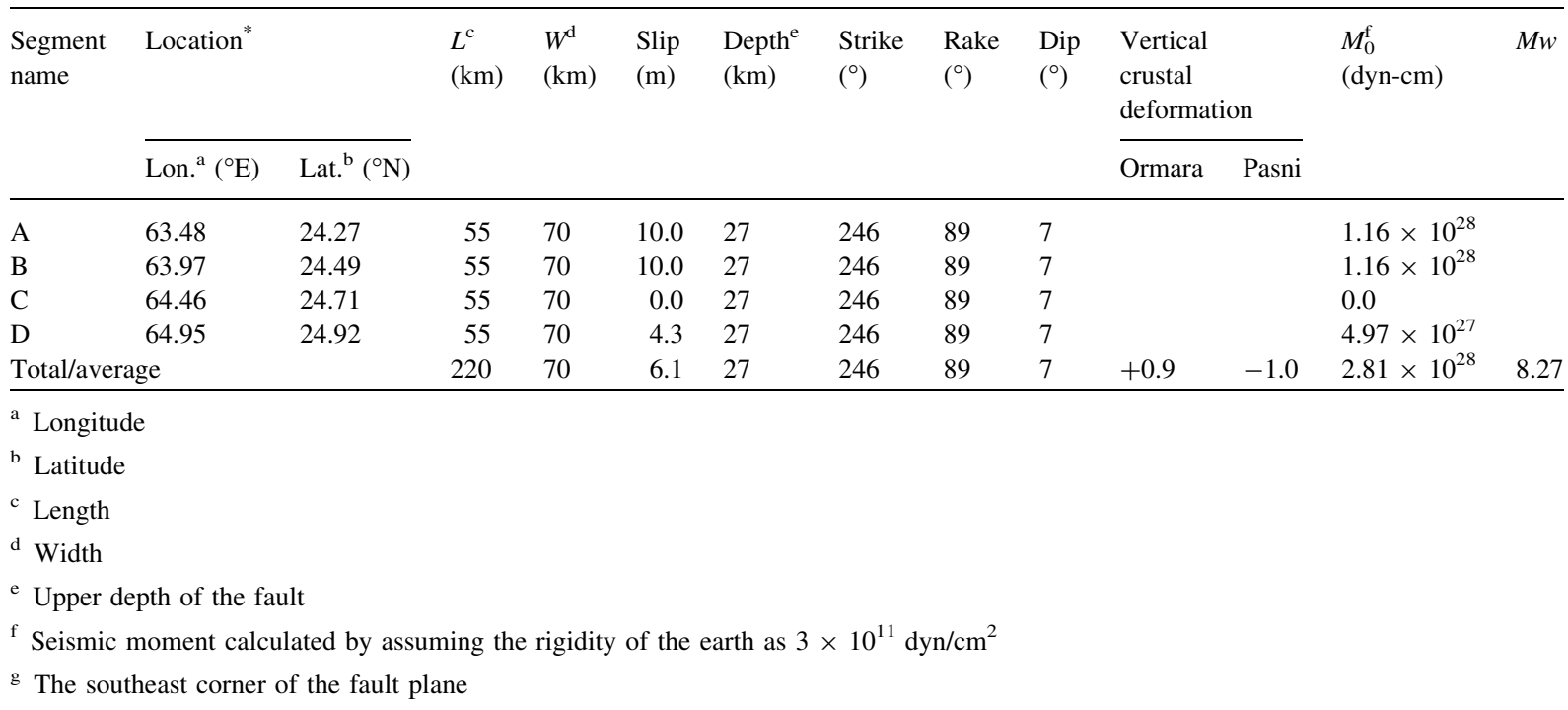

\section{Discussion}

\subsection{Veracity of the Coseismic Uplift and Seismological Data}

We extended the tsunami source along the fault strike up to the Ormara coast following the report of coseismic uplift at Ormara by PAGE et al. (1979), but the final calculated slip amount on the near-shore subfault (i.e., subfault D in Fig. 7b, right) is based on the tide gauge records. Inversion of observed tide gauge records at Karachi alone, Mumbai alone, and both waveforms resulted in slip amounts of 3.1, 3.1, and $4.3 \mathrm{~m}$, respectively, for subfault D (Fig. 6c-e). As the slip on subfault $\mathrm{D}$ has been calculated independently from coastal deformation data, it can be used to examine the accuracy of the coseismic uplift of 1-3 $\mathrm{m}$ at Ormara reported by PAGE et al. (1979). Our final fault model has a slip of $4.3 \mathrm{~m}$ on subfault $\mathrm{D}$, which produces a coseismic uplift of around $1 \mathrm{~m}$ at Ormara (Table 3; Fig. 7c, right). This uplift is in the range (1-3 m) of coseismic uplift reported by PAGE et al. (1979). Our proposed source yields a moment magnitude of around $M w 8.3$ for the earthquake (Table 3), which is the maximum value of the magnitude range (8.0-8.3) reported in the literature for the 27 November 1945 earthquake (BYRNE et al. 1992; RICHTER 1958; DUdA 1965).

\subsection{Near-Field Observations of the 1945 Makran Tsunami}

A runup height of $12-15 \mathrm{~m}$ was reported in the near field due to the Makran tsunami of November 1945 (Pendse 1946). However, our proposed source (Table 3) generates a maximum onshore wave amplitude of around 5-6 $\mathrm{m}$ in the near field (Fig. 7a), which is an approximation of tsunami runup. It was not the aim of this study to explain all of the observations other than the tsunami waveforms at tide gauges and coseismic deformation data. Figure $2 \mathrm{a}$ shows that the two available tide gauge stations are located far from the source on a wide continental shelf which is an extended shallow-water region. Therefore, it seems unlikely that any waves generated by local phenomena such as submarine landslides could reach them. We thus expect to receive only waves generated by the seismic source at the two examined stations, as was the case for the waves recorded on the Japan coast due to the 1998 Papua New Guinea tsunami (Satake and TANioka 2003). In fact, our modeling using the two available tsunami waveforms explains mainly the tectonic source of the Makran tsunami of 1945. Separate studies are needed to explain the near-field observations. It has previously been speculated that the extreme runup height of $12-15 \mathrm{~m}$ was the result of a possible submarine 
landslide or a splay fault branching from the plate boundary (e.g., Heidarzadeh et al. 2008a).

\subsection{Our Source Model in Comparison with Other Studies}

As discussed in Sect. 1, some source models have been proposed by other authors for the Makran tsunami of 1945 (Table 1; Fig. 4a). Our source model is different from others in several ways: (1) our model has a heterogeneous slip distribution, whereas other sources have a uniform slip; (2) our model is extended to deep water with water depth of around 3,000 m, while most of the other sources lack such offshore slip; and (3) our source model also extends to near coast so that it produces an uplift of around $1 \mathrm{~m}$ at Ormara, whereas all other sources generate no uplift there. Our source model implies a moment magnitude of $M w 8.3$ (Table 3), which is larger than that of the source HDZ-2009 (Table 1) but smaller than that of the source HDZ-2008. Despite these differences, the maximum coastal wave height produced by our source (Fig. 7a) is close to those of the sources HDZ-2008 (Fig. 6 in Heidarzadeh et al. 2008a) and HDZ-2009 (Fig. 6 in Heidarzadeh et al. 2009a). In all cases, the maximum coastal wave amplitudes in the near field are in the range of 4-6 m.

\section{Conclusions}

Spectral analysis, tsunami forward modeling, as well as tsunami inversion analysis were employed to constrain the source of the Makran tsunami of November 1945 using recently available tsunami waveforms recorded on tide gauges and coseismic deformation data. Main findings are:

1. The tsunami peak periods were $22-25,40-50$, and 85-90 min. At Karachi, the governing period was 40-50 min, whereas it was around $22 \mathrm{~min}$ at Mumbai. At Port Victoria (Seychelles), the period of the first wave was $21 \mathrm{~min}$. The distribution of tsunami energy in a wide period band of 22-90 $\mathrm{min}$ may indicate that the tsunami source fault possibly lays from near-shore shallow waters of around $100 \mathrm{~m}$ to offshore deep waters of around 3,000 m.
2. Tsunami modeling using previously published source models showed that only a source located offshore at water depth of around 2,000-3,000 m is able to reproduce the 22-min signal observed at Mumbai. However, all of the previously published sources fail to reproduce the 1-3 m uplift at Ormara.

3. Sensitivity analysis gives us the two end points of the earthquake rupture zone: on the one hand, the seafloor deformation caused by the earthquake needs to be located in offshore deep water at water depth of around 2,000-3,000 $\mathrm{m}$ in order to reproduce the first 22-min signal at Mumbai; and on the other hand, the deformation zone needs to be extended up to Ormara in order to reproduce the observed 1-3 $\mathrm{m}$ of coseismic uplift there.

4. Based on the inversion of the available tsunami waveforms recorded on tide gauges at Mumbai and Karachi, we propose a four-segment fault with varying slip amounts as the tsunami source. This source includes a slip of $4.3 \mathrm{~m}$ onshore near Ormara (Pakistan) and a slip of $10 \mathrm{~m}$ offshore at water depth of around $3,000 \mathrm{~m}$. The total length of the fault is $220 \mathrm{~km}$, and the average slip is $6.1 \mathrm{~m}$. Other source parameters include width of $70 \mathrm{~km}$, southeast corner of the fault plane at $64.941^{\circ} \mathrm{E}$ and $24.923^{\circ} \mathrm{N}$, top depth of $27 \mathrm{~km}$, dip angle of $7^{\circ}$, slip angle of $89^{\circ}$, and strike angle of $246^{\circ}$. This source, first, reproduces fairly well the observed waveforms at Mumbai and Karachi, second, produces $\sim 1$ m of uplift at Ormara and $\sim 1 \mathrm{~m}$ of subsidence at Pasni, and third, gives a magnitude of 8.3 for the earthquake, which is in the acceptable range.

5. The computed $1 \mathrm{~m}$ of uplift at Ormara is in the range of the uplift of $1-3 \mathrm{~m}$ reported in the literature.

6. As the tide gauge stations were located in the far field inside an extended shallow region, our proposed source explains mainly the tectonic source of the tsunami.

\section{Acknowledgments}

The tide gauge records of the Makran tsunami of November 1945 at Karachi and Mumbai were first 
retrieved by NeETU et al. (2011) and were digitized here for this study. We thank two anonymous reviewers for their constructive comments. We are grateful to Dr. Hermann M. Fritz (the editor) and Dr. Takeo Ishibe for their critical reviews of the manuscript. This study was supported by the Japan Society for the Promotion of Science (JSPS).

\section{REFERENCES}

Beer, A., and Stagg, J.M. (1946), Seismic sea-wave of November 27, 1945, Nature 158, 63.

Bell, C., Vassie, J.M., and Woodworth, P.L. (2000), POL/PSMSL Tidal Analysis Software Kit 2000 (TASK-2000), Permanent Service for Mean Sea Level. CCMS Proudman Oceanographic Laboratory, UK, 22p.

Borrero, J. C., and Greer, S. D. (2013), Comparison of the 2010 Chile and 2011 Japan tsunamis in the far field, Pure Appl. Geophys. 170 (6-8), 1249-1274.

Byrne, D.E., Sykes, L.R., and Davis, D.M. (1992), Great thrust earthquakes and aseismic slip along the plate boundary of the Makran subduction zone, J. Geophys. Res. 97 (B1), 449-478.

Donato, S. V., Reinhardt, E. G., Boyce, J. I., PilarczyK, J. E., and JupP, B. P. (2009), Particle-size distribution of inferred tsunami deposits in Sur Lagoon, Sultanate of Oman, Mar. Geol. 257(1), 54-64.

DudA, S. J. (1965), Secular seismic energy release in the circumPacific belt, Tectonophysics 2(5), 409-452.

Fuji, Y., Satake, K., Sakai. S, Shinohara, M., and Kanazawa, T. (2011). Tsunami source of the 2011 off the Pacific coast of Tohoku Earthquake, Earth Planets Space 63, 815-820.

Fritz, H.M, Blount, C.D., Albusaidi, F.B., Al-harthy, A.H.M. (2010). Cyclone Gonu Storm Surge in Oman, Estuar. Coast. Shelf Sci., 86(1), 102-106.

Gutenberg, B., and Richter, C.F. (1954), Seismicity of the earth and associated phenomena, 2nd edition, Princeton University Press.

Heck, N.H. (1947), List of seismic sea waves, Bull. Seismol. Soc. Am. 37(4), 269-286.

Heidarzadeh, M., Pirooz, M.D., Zaker, N.H., Yalciner, A.C., Mokhtari, M., and Esmaeily, A. (2008a), Historical tsunami in the Makran subduction zone off the southern coasts of Iran and Pakistan and results of numerical modeling, Ocean Eng. $35(8$ \& 9), 774-786.

Heidarzadeh, M., Pirooz, M.D., Zaker, N.H., Synolakis, C.E. (2008b), Evaluating tsunami hazard in the northwestern Indian Ocean. Pure Appl. Geophys. 165 (11-12), 2045-2058.

Heidarzadeh, M., Pirooz, M.D., Zaker, N.H., and Yalciner, A.C. (2009a), Preliminary estimation of the tsunami hazards associated with the Makran subduction zone at the northwestern Indian Ocean, Nat. Hazards 48(2), 229-243.

Heidarzadeh, M., Pirooz, M.D., and Zaker, N. H. (2009b), Modeling the near-field effects of the worst-case tsunami in the Makran subduction zone, Ocean Eng. 36(5), 368-376.

Heidarzadeh, M., and Satake, K. (2013a), The 21 May 2003 Tsunami in the Western Mediterranean Sea: Statistical and Wavelet Analyses, Pure Appl. Geophys. 170 (9-10), 1449-1462.
Heidarzadeh, M., and Satake, K. (2013b), Waveform and Spectral Analyses of the 2011 Japan Tsunami Records on Tide Gauge and DART Stations Across the Pacific Ocean, Pure Appl. Geophys. 170 (6-8), 1275-1293.

Heidarzadeh, M., and Kijko, A. (2011), A probabilistic tsunami hazard assessment for the Makran subduction zone at the northwestern Indian Ocean, Nat. Hazards 56(3), 577-593.

Heidarzadeh, M., and Satake, K. (2014), Possible sources of the tsunami observed in the northwestern Indian Ocean following the 2013 September 24 Mw 7.7 Pakistan inland earthquake, Geophys. J. Int. 199 (2), 752-766.

Hoffmann, G., Rupprechter, N., Albalushi, N., Grutzner, C., REICHERTER, K. (2013), The impact of the 1945 Makran tsunami along the coastlines of the Arabian Sea (Northern Indian Ocean) - a review, Z. Geomorphologie 57(4), 257-277.

IOC, IHO, and BODC (2003), Centenary edition of the GEBCO digital atlas, published on CD-ROM on behalf of the Intergovernmental Oceanographic Commission and the International Hydrographic Organization as part of the general bathymetric chart of the oceans, British Oceanographic Data Centre, Liverpool.

Jaiswal, R. K., Singh, A. P., and Rastogi, B. K. (2009), Simulation of the Arabian Sea tsunami propagation generated due to 1945 Makran earthquake and its effect on western parts of Gujarat (India), Nat. Hazards 48(2), 245-258.

KREYszig, E. (2010), Advanced engineering mathematics, $10^{\text {th }}$ edition, Wiley, New York, USA.

MATHWORKs (2014), MATLAB user manual, MathWorks Inc., MA, USA, $282 \mathrm{p}$.

MoкHTARI, M. (2014), The role of splay faulting in increasing the devastation effect of tsunami hazard in Makran, Oman Sea, Arab. J. Geosci., pp 8. doi:10.1007/s12517-014-1375-1

Nature (1945), Earthquake in the Arabian Sea, Nature 156, 712-713.

Neetu, S., Suresh, I., Shankar, R., Nagarajan, B., Sharma, R., Shenoi, S. S. C., Unnikrishnan, A.S., and Sundar, D. (2011), Trapped waves of the 27 November 1945 Makran tsunami: observations and numerical modeling, Nat. Hazards 59(3), 1609-1618.

ОкаDA, Y. (1985), Surface deformation due to shear and tensile faults in a half space, Bull. Seismol. Soc. Am. 75(4), 1135-1154.

Okal, E.A., Fritz, H.M., RaAd, P.E., Synolakis, C.E., Al-shijbi, Y., Al-SAIFI, M. (2006). Field survey of the 2004 Indonesian Tsunami in Oman, Earthq. Spectra 22(S3), S203-S218.

Page, W. D., Alt, J. N., Cluff, L. S., and Plafker, G. (1979), Evidence for the recurrence of large-magnitude earthquakes along the Makran coast of Iran and Pakistan, Tectonophysics 52(1), 533-547.

Pendse, C. G. (1946), The Mekran earthquake of the 28th November 1945, India Meteorol. Depart. Sci. Notes 10(125), 141-145.

Pilarczyk, J. E., and Reinhardt, E. G. (2012), Testing foraminiferal taphonomy as a tsunami indicator in a shallow arid system lagoon: Sur, Sultanate of Oman, Mar. Geol. 295, 128-136.

QuitTMEYER, R. C., and JАСOB, K. H. (1979), Historical and modern seismicity of Pakistan, Afghanistan, northwestern India, and southeastern Iran, Bull. Seismol. Soc. Am. 69(3), 773-823.

Rabinovich, A.B. (1997), Spectral analysis of tsunami waves: Separation of source and topography effects, J. Geophys. Res. 102(12), 663-676. 
Rabinovich, A.B., and Thomson, R.E. (2007), The 26 December 2004 Sumatra tsunami: analysis of tide gauge data from the World Ocean Part 1. Indian Ocean and South Africa, Pure Appl. Geophys. 164, 261-308.

Rajendran, C. P., Rajendran, K., Shah-hosseini, M., Beni, A. N., Nautiyal, C. M., and ANDrEws, R. (2013), The hazard potential of the western segment of the Makran subduction zone, northern Arabian Sea, Nat. Hazards 65(1), 219-239.

Richter, C. F. (1958), Elementary Seismology, W.H. Freeman, San Francisco.

SATAKe, K. (1987), Inversion of tsunami waveforms for the estimation of a fault heterogeneity: Method and numerical experiments, J. Phys. Earth, 35(3), 241-254.

Satake, K., Fujil, Y., Harada, T., Namegaya, Y. (2013), Time and space distribution of coseismic slip of the 2011 Tohoku earthquake as inferred from tsunami waveform data, Bull. Seismol. Soc. Am. 103(2B), 1473-1492.

SAtake, K., and TAnioka, Y. (2003), The July 1998 Papua New Guinea earthquake: Mechanism and quantification of unusual tsunami generation, Pure Appl. Geophys. 160(10-11), 2087-2118.

Shah-hosseini, M., Morhange, C., Naderi Beni, A., Marriner, N., Lahijani, H., Hamzeh, M., and Sabatier, F. (2011), Coastal boulders as evidence for high-energy waves on the Iranian coast of Makran, Marine Geology 290(1), 17-28.
Smith, G. L., Mcneill, L. C., Wang, K., He, J., and Henstock, T. J. (2013), Thermal structure and megathrust seismogenic potential of the Makran subduction zone, Geophys. Res. Lett. 40(8), 1528-1533.

Takahashi, T., Takahashi, T., Shuto, N., Imamura, F., and Ortiz, M. (1995), Source models for the 1993 Hokkaido Nansei-Oki earthquake tsunami, Pure Appl. Geophys. 144(3-4), 747-767.

TANIOKA, Y. and SATAKe, K. (1996), Tsunami generation by horizontal displacement of ocean bottom, Geophys. Res. Lett. 23, 861-864.

Tinti, S., Armigliato, A., Bortolucci, E., and Piatanesi, A. (1999), Identification of the source fault of the 1908 Messina earthquake through tsunami modelling. Is it a possible task?, Phys. Chem. Earth 24(5), 417-421.

Torrence, C. and Compo, G. (1998), A practical guide to wavelet analysis, Bull. Am. Met. Soc., 79, 61-78.

Welch, P.D. (1967), The Use of Fast Fourier Transform for the Estimation of Power Spectra: A Method Based on Time Averaging Over Short, Modified Periodograms, IEEE Trans. Audio Electroacoustics $A U-15,70-73$.

Yalciner, A.C., Pelinovsky, E., Talipova, T., Kurkin, A., KozelKov, A., and Zaitsev, A. (2004), Tsunamis in the Black Sea: comparison of the historical, instrumental, and numerical data. J. Geophys. Res. 109 (12), 2003-2113. 